\title{
ENGAÑO EN LA ESTAFA: ¿UNA PUESTA EN ESCENA?
}

\author{
Gustavo Balmaceda Hoyos* \\ Con la colaboración de Ignacio Araya Paredes ${ }^{* *}$
}

1. Introducción; 2. Algunas notas sobre el engaño; 3. Determinación del engaño jurídico-penalmente relevante: 3.1.- Teoría objetivo-subjetiva; 3.2.- Estafa e imputación objetiva: 3.3.- Estafa como lesión de un derecho a la verdad; 4.-Conclusiones.

\section{Introducción}

En un sistema no alemán de la estafa nadie puede negar que el engaño necesita cierta entidad para ser típico. Tradicionalmente, en este tema los sistemas latinos han optado por el antiguo sistema francés consistente en que el engaño jurídicopenal a efectos de la estafa tiene que determinarse con un muy exigente filtro normativo: la teoría de la mise en scéne. ¿Hoy en día convendrá seguir ciñéndonos a este sistema? A la búsqueda de una posible solución se dirige el presente trabajo.

\section{Algunas notas sobre el engaño}

Ya en la época de la gestación dogmática del delito de estafa eran evidentes las diferencias existentes en la doctrina en relación con este punto, disputa que, en esencia, existe hasta el día de hoy. ${ }^{2}$ En efecto, el debate consiste básicamente en interpretar a la estafa como un delito que exige una calificación del engaño y cierta diligencia de la víctima, ${ }^{3}$ o como un hecho punible que deba proteger a toda clase

\footnotetext{
* Abogado (Universidad de Chile). Doctor en Derecho Penal (Universidad de Salamanca, España). Profesor de Derecho Penal y Procesal Penal (Universidad de los Andes). Coordinador del Magíster en Derecho Penal de la Universidad de Chile.

** Estudiante de Derecho (Universidad de Chile). Ayudante de Derecho Penal (Universidad de Chile).

${ }^{1}$ Por ello siguen vigentes las palabras de QUINTANO RIPOLLÉS, 1977, p. 590, al decir: «La entidad del engaño, su cantidad, ha de ser medida no exactamente con cómputos objetivamente cuantitativos, sino en relación con su eficacia operativa. Asunto que de siempre ha dividido la opinión de los tratadistas y que, como tantos otros, está aún lejos de haberse resuelto de modo plenamente satisfactorio».

2 Por ello siguen vigentes las palabras de QUINTANO RIPOLLÉS, 1977, p. 590, al decir: «La entidad del engaño, su cantidad, ha de ser medida no exactamente con cómputos objetivamente cuantitativos, sino en relación con su eficacia operativa. Asunto que de siempre ha dividido la opinión de los tratadistas y que, como tantos otros, está aún lejos de haberse resuelto de modo plenamente satisfactorio».

3 Así, la mayoría de la doctrina y jurisprudencia chilena. Por todos, ETCHEBERRY, 1998, p. 391 ss, y 406 ss. Asimismo, véase Sentencia del Sexto Tribunal de Juicio Oral en lo Penal de Talca
} 
Balmaceda / Araya - Engaño en la estafa: ¿una puesta en escena?

de víctimas, problema que en la época contemporánea se trata en el marco de la victimodogmática ${ }^{4}$ y en el seno de la teoría de la imputación objetiva ${ }^{5}$-esta última seguimos en este trabajo, como veremos- ${ }^{-}$.

De esta manera, -según algunos- la aplicación de la victimodogmática a la estafa podría estimarse como un paso adelante, pues introduciría la responsabilidad de la víctima en el estudio de la tipicidad, y con ello se favorecería el rechazo del sistema causalista que estimaba al delito como un proceso unilateral de generación de un resultado lesivo. ${ }^{6}$

No obstante, la utilización del principio de subsidiariedad por parte de la victimodogmática no parece correcta desde un punto de vista metodológico. ${ }^{7}$ Entonces, podemos decir que el único aporte que efectuaría dice relación con llamar la atención en que las posibilidades de autoprotección de la víctima podrían ser relevantes en la conceptualización de la conducta típica y, con ello, podría ser útil para delimitar los ámbitos de responsabilidad entre autor y víctima, en relación con los cuales debería ponerse atención en un marco más adecuado, es decir, en el juicio de tipicidad del comportamiento (o según otra terminología: en la imputación objetiva de la conducta). ${ }^{8}$

23/04/2008; Sentencia de la Corte de Apelaciones de La Serena 17/12/2002; Sentencia de la Corte de Apelaciones de San Miguel 03/12/2007; Sentencias de la Corte de Apelaciones de Santiago 06/12/2007; 31/01/2008; 14/11/2008; Sentencia de la Corte de Apelaciones de Valparaíso 08/04/2008; Sentencias de la Corte de Apelaciones de Temuco 30/06/2008; 07/07/2008; Sentencia de la Corte de Apelaciones de Concepción 07/07/2008; Sentencia de la Corte de Apelaciones de Arica 23/07/2008; Sentencias de la Corte Suprema 21/11/2007; 17/06/2008; jurisprudencia citada en MERA / CASTRO, 2007, p. 252 ss, y 424 ss.

${ }^{4}$ Sin embargo, hoy por hoy, se afirma que contemplar al delito solamente desde una perspectiva unidireccional ha fracasado, pues se estima que la victimodogmática se limita a dotar de un nuevo enfoque a la dogmática, a saber, el de que la víctima puede haber contribuido responsablemente a la configuración del delito. Dicho con otras palabras, se afirma que únicamente de ella queda una perspectiva que cabe incorporar a un marco más adecuado, el de la teoría de la imputación objetiva (así, CANCIO MELIÁ, 2001, p. 242 ss, y 254 ss; similar, FERNÁNDEZ DÍAZ, 2005, p. 191 ss).

5 De esta opinión, pero conforme con una «imputación objetiva de la conducta», PASTOR MUÑOZ, 2004, p. 99, 101, y 102 ss, donde plantea que, desde un principio, los modos de formular el planteamiento básico a estos efectos son diferentes, pero responden a una misma concepción: que la otra cara de la moneda de la calificación del engaño consiste en exigir a la víctima cierta diligencia destinada a desenmascarar la inveracidad, característica que la autora resalta, pues afirma que la adopción de un modelo de víctima es un punto de vital importancia en la normativización del engaño.

6 Véase CHOCLÁN MONTALVO, 2000, p. 108 ss.

7 En sentido similar, señalando que no puede ser un criterio decisivo, ARZT, 1984, p. 105 ss, donde expone -con acierto- que, por regla general, la victimodogmática no puede tener como consecuencia la impunidad, sino una mera «atenuación» de la pena.

${ }^{8}$ Así, PASTOR MUÑOZ, 2004, p. 117-118. 
Como consideración general, tenemos que subrayar que el engaño constituye la esencia del delito de estafa, ${ }^{9}$ pues ofrece una ilimitada variedad de ejemplos que son fruto del ingenio y de la picaresca que se da en la vida real y que se incardina en el seno de un pacto o relación contractual preparada con fin defraudatorio (no se olvide que el popularmente conocido "cuento del tío", a fin de cuentas, es un contrato). ${ }^{10}$ Inclusive, se ha manifestado que "elemento característico del tipo objetivo de estafa -y que permite diferenciarlo de los demás delitos contra el patrimonio, puesto que le da fisonomía propia- es el engaño. Sin su concurrencia no se concibe la estafa, a tal punto que vulgarmente hasta se llega a identificar este requisito con el delito mismo". ${ }^{11}$

En este mismo sentido, el Tribunal Supremo español ha expresado las siguientes ideas:

(a) La estafa es una maniobra torticera y falaz por medio de la cual el agente, ocultando la realidad, juega dentro de la apariencia para ganar la voluntad del perjudicado, haciéndolo creer y aceptar lo que no es verdadero; ${ }^{12}$

(b) El delito de estafa reclama la existencia de un artificio, creado por alguien con objeto de hacer pasar por cierta una situación que no lo es, como forma de inducir a error a otro que, en virtud de la aceptación de tal apariencia como real, dispone de algún bien a favor del primero, que se enriquece ilícitamente, con el consiguiente perjuicio patrimonial para el segundo; ${ }^{13}$

(c) Es una relación interactiva montada sobre la simulación de circunstancias que no existen o la disimulación de las realmente existentes, como medio para mover la voluntad de quien es titular de bienes o derechos o que puede disponer de los mismos en términos que no se habrían dado de resultar conocida la real naturaleza de la operación $;{ }^{14}$

(d) En la estafa el engaño es utilizado para producir el error en la otra persona con que se relaciona, que es inducida así a realizar un determinado desprendimiento patrimonial del que, en relación de causa a efecto, se beneficia el instigador de la operación, ${ }^{15}$

(e) Supone, en su modalidad genérica, la puesta en marcha de una maquinación insidiosa por parte del sujeto agente que a merced de su

\footnotetext{
${ }^{9}$ Para el estudio de los rasgos criminológicos del engaño en la estafa, confróntese HENTIG, 1980, p. 59 ss, y 123 ss. En este sentido, la jurisprudencia chilena (Véase Sentencia de la Corte de Apelaciones de Valdivia 28/10/1986; Sentencia de la Corte de Apelaciones de Punta Arenas 27/10/1989; Sentencia de la Corte de Apelaciones de Santiago 20/03/2007; Sentencias de la Corte Suprema 05/06/2006; 26/06/2008).

10 En esta dirección, la jurisprudencia española y chilena, así, Sentencia del Tribunal Supremo español 16/07/1999; Sentencias de la Corte Suprema 05/09/2006; 6/08/2007.

${ }^{11}$ ROMERO, 2007, p. 109. Similar, ARROYO DE LAS HERAS, 2005, p. 22.

${ }_{12}$ Confróntese Sentencias del Tribunal Supremo español 17/11/1997; 28/03/2000.

${ }^{13}$ Véase Sentencia del Tribunal Supremo español 28/01/2005.

${ }^{14}$ Confróntese Sentencia del Tribunal Supremo español 23/03/2005.

15 Véase Sentencias del Tribunal Supremo español 20/07/1998; 28/03/2000; 6/07/2004.
} 
Balmaceda / Araya - Engaño en la estafa: ¿una puesta en escena?

ingenio crea una trama a espaldas del afectado, persiguiendo como resultado final un desplazamiento patrimonial a su favor, en perjuicio de aquél, o de un tercero; ${ }^{16}$

(f) En el delito de estafa se ha de quebrar la barrera defensiva constituida por la inicial desconfianza que, en mayor o menor grado, inspira el extraño en cuyas manos se pone lo que nos pertenece, $;^{17}$

(g) Que el alma de la estafa es el engaño, es decir, cualquier ardid, argucia o trato que se utilice para inducir a error y provocar un conocimiento inexacto y deformado de la realidad, que determina a otro a realizar la entrega de un bien o la realización de una prestación, que de otra manera no se hubiera realizado; ${ }^{18}$

(h) Que posee una gran variedad de manifestaciones concretas, es decir: el engaño se concibe con un criterio de gran laxitud, sin recurrir a enunciados ejemplificativos, como se hacía en anteriores Códigos penales, dada la ilimitada variedad de supuestos que la vida real ofrece; ${ }^{19} \mathrm{y}$,

(j) Afirma también el Tribunal Supremo español que las modalidades de su aparición se extienden a un amplio espectro de manifestaciones que abarcan cualquier tipo de ardid, maniobra o maquinación insidiosa, falacia o mendacidad con que se crea una apariencia de verdad que se despliega sobre la voluntad del sujeto pasivo para provocar el desplazamiento patrimonial. $^{20}$

Así, y en sentido amplio, la jurisprudencia española ${ }^{21}$ afirma que para entenderse el concepto de engaño debe comprenderse, usualmente, como la acción y el efecto de hacer creer a alguien algo que no es verdad; y asimismo, de forma análoga el Diccionario de la Real Academia estima por tal la "falta de verdad en lo que se dice, hace, cree, piensa o discurre", y, por engañar, "dar a la mentira apariencia de verdad" 22 . De esta forma, desde una perspectiva jurisprudencial, el engaño sería

\footnotetext{
16 Confróntese Sentencia del Tribunal Supremo español 14/01/2003. En el mismo sentido, la jurisprudencia chilena (Véase Sentencia de la Corte de Apelaciones de San Miguel 22/03/1990).

17 Véase Sentencia del Tribunal Supremo español 3/04/2000.

18 Confróntese Sentencia del Tribunal Supremo español 8/04/2002.

${ }^{19}$ Véase Sentencia del Tribunal Supremo español 6/03/2000.

20 Confróntese Sentencias del Tribunal Supremo español 21/01/2002; 23/10/2002; 28/01/2004. Sin embargo, la jurisprudencia chilena ha señalado, para el caso del artículo $473 \mathrm{CP}$ (que, a nuestro juicio, constituye la llamada estafa residual) no se requiere, a diferencia de lo que ocurre con la estafa tipificada en el artículo 468 CP, de un ardid (Confróntense Sentencia de la Corte de Apelaciones de Santiago 03/01/1986; Sentencia de la Corte de Apelaciones de San Miguel 22/07/1986; Sentencia de la Corte Suprema 12/12/2007; Sentencia de la Corte de Apelaciones de Concepción 25/01/2008. En contra, Sentencia de la Corte de Apelaciones de Talca 06/08/2007; Sentencia de la Corte de Apelaciones de Valparaíso 03/06/2008).

${ }^{21}$ En este sentido, Sentencias del Tribunal Supremo español 4/02/2002; 5/02/2004. Similar, la jurisprudencia chilena (véase Sentencia de la Corte de Apelaciones de Punta Arenas 27/11/1989; Sentencia de la Corte Suprema 26/03/2007; jurisprudencia citada por GARRIDO IRACHETA, 1999, p. 14).

22 Diccionario de la Lengua Española. Vigésima segunda edición. Disponible en www.rae.es (consultado: 17/03/10).
} 
toda afirmación verdadera de un hecho en realidad falso, o bien, el ocultamiento o deformación de hechos verdaderos. ${ }^{23}$

En esta dirección amplia del concepto de engaño, la jurisprudencia española ${ }^{24}$ también ha manifestado que el mismo consiste en cualquier tipo de ardid, maniobra o maquinación, mendacidad, fabulación o artificio del agente, determinante del aprovechamiento patrimonial en perjuicio de otro, y que es extensivo el concepto legal a "cualquier falta de verdad o simulación", "cualquiera que sea su modalidad", apariencia de verdad que determina a realizar una entrega de cosa, dinero o prestación, que de otra manera no se hubiese realizado.

Finalmente, el criterio del Tribunal Supremo español ${ }^{25}$ para determinar el concepto de engaño, junto a la concepción en sentido amplio a que hemos hecho referencia, en un sentido más restringido, ha sido la de comprenderlo dentro de las siguientes modalidades:

(a) Como ausencia de verdad, es decir, como la falta de verdad suficiente y bastante para producir el error como conocimiento viciado de la realidad;

(b) Como ocultación de la verdad, señalando que existe tal situación cuando el autor afirma como verdadero algo que no lo es, o cuando oculta o deforma algo verdadero para impedir que el otro lo conozca; y, en relación con el problema, asimismo dice que el engaño es una maniobra torticera y falaz mediante la cual el agente, ocultando la realidad, juega dentro de la apariencia para ganar la voluntad del perjudicado, haciéndole creer y aceptar lo que no es verdadero;

(c) Como apariencia de verdad, sosteniendo que el engaño consiste en la falsedad o falta de verdad en lo que se dice o hace, en la apariencia de verdad o, en la maquinación insidiosa desplegada en la voluntad del sujeto pasivo para provocar el desplazamiento patrimonial; o, expresando también, que el engaño consiste en una asechanza, trampa o añagaza con la que se trata de crear en el sujeto pasivo una sensación de realidad que no se corresponde con las circunstancias del caso ni con las cualidades o condiciones personales del sujeto activo; $y$,

\footnotetext{
23 De forma semejante, señalando que los artificios e insidias del art. $640 \mathrm{CP}$ italiano deben configurarse de manera bastante «extensa», se pronuncian la doctrina y jurisprudencia italianas (véase, por todos, FIANDACA / MUSCO, 2005, p. 173-174; PECORELLA, 2006, NM 7; y las sentencias allí citadas).

${ }^{24}$ Así, Sentencia del Tribunal Supremo español 15/02/2005. Diferente, la jurisprudencia chilena, que insiste -a nuestro juicio equivocadamente, como veremos - en restringir el concepto de engaño (Véase Sentencia de la Corte de Apelaciones de Santiago 12/07/2004; Sentencia de la Corte de Apelaciones de San Miguel 26/11/2007; jurisprudencia citada por GARRIDO IRACHETA, 1999, p. $14 \mathrm{ss})$.

25 Confróntese, por todas, Sentencias del Tribunal Supremo español 5/11/1998; 27/01/1999; 6/05/1999; 13/05/1997; 5/05/1998; 21/10/1998; 1/03/1999; 24/03/1999; 4/05/1999; 2/12/2003; 28/01/2004; 20/07/1998; 5/11/1998; 27/01/1999; 28/04/1999; 6/05/1999; 2/03/1998; 1/12/1999; 9/06/1999; 1/03/1999; 7/05/2004; 6/07/2004; 5/11/2004; 28/01/2005.
} 
Balmaceda / Araya - Engaño en la estafa: ¿una puesta en escena?

(d) Por último, como simulación de lo que no existe o disimulación de lo que existe, apuntando que el engaño consiste en cualquier conducta contraria a la verdad, ya sea por disimular lo que existe o por simular lo que no existe, con tal que la conducta sea adecuada para generar el error de quien realiza el perjudicial acto de disposición.

En esta misma dirección, esto es, en un sentido jurídico-penal más preciso, puede decirse que el engaño consiste en la "simulación o disimulación capaz de inducir a error a una o varias personas", "26 que -en opinión de la jurisprudencia española ${ }^{27}$ - debe versar respecto a "hechos" y no sobre "valoraciones". ${ }^{28}$ Nosotros sostenemos, como veremos en este mismo apartado, que puede recaer sobre ambos, siempre y cuando se cumplan los elementos típicos y demás requisitos de imputación objetiva.

En este orden de cosas, el engaño en la estafa debe ser la causa ${ }^{29}$-en el sentido de la teoría de la condición- de la disposición patrimonial perjudicial, ${ }^{30}$

\footnotetext{
${ }^{26}$ ANTÓN ONECA, 1958, p. 61.

${ }^{27}$ Sobre este punto, el Tribunal Supremo español ha afirmado que en el concepto de engaño no se comprenden los hechos futuros ni los juicios de valor, porque sostiene que en la medida en que sólo los hechos pueden ser verdaderos o falsos, el objeto del engaño debe ser en todo caso un hecho. Y así, ha entendido que un hecho es algo que ha ocurrido o que existe, que ha llegado a ocurrir y llegado a ser realidad. En consecuencia, expresa que si el engaño se reduce a la afirmación de un hecho falso o al ocultamiento de un hecho verdadero relevante para la decisión del sujeto pasivo, quedan descartados como objeto de engaño los «hechos futuros» y los juicios de valor, en la medida en la que no son hechos, sin perjuicio de ciertas excepciones admitidas en la doctrina respecto de juicios de valor que comportan afirmaciones tácticas (Véase Sentencia del Tribunal Supremo español 5/02/2004).

28 Así también, ROMERO, 2007, p. 115 ss; BACIGALUPO, 2007, p. 2000; BACIGALUPO, 2007b, p. 166, SUÁREZ GONZÁLEZ, 1997, p. 709. Sin embargo, la mayoría de la doctrina española, en contra, aboga por su aceptación dentro del concepto de engaño, véase, por todos, ANTÓN ONECA, 1958, p. 64; GONZÁLEZ RUS, 1986, p. 281; GONZÁLEZ RUS, 2005, p. 511; RODRÍGUEZ DEVESA / SERRANO GÓMEZ, 1995, p. 502; GARCÍA RIVAS, 2005, p. 27. En Alemania, por su parte, la opinión absolutamente dominante afirma que no se pueden admitir los juicios de valor en el engaño a efectos del delito de estafa. Así, TIEDEMANN, 1999, NMs 7 ss, donde expresa que los hechos versan sobre algo pasado o presente que se manifiesta en la vida real y que, por eso, pueden probarse. Por ello, apunta que deben excluirse las declaraciones sobre hechos «futuros» y las meras «valoraciones». En el mismo sentido, véase CRAMER / PERRON, 2006, NMs 8 ss, donde manifiestan que un comportamiento engañoso únicamente puede tener como punto de referencia unos «hechos», los que definen como todos los sucesos concretos, pasados o presentes, o las situaciones del mundo exterior y del fuero interno con cierta certeza objetiva. Finalmente, estos últimos autores rechazan como hechos los acontecimientos futuros, pero afirman que los conocimientos científicos que admiten conclusiones sobre hechos futuros hay que comprenderlos como hechos del presente.

${ }^{29}$ En este sentido, la jurisprudencia española manifiesta que se exige un «engaño antecedente», es decir, que el delito de estafa requiere un engaño precedente o concurrente, señalando que es la espina dorsal de la estafa (Véase Sentencias del Tribunal Supremo español 30/10/1997; 7/11/1997; 4/02/1998; 17/07/1998; 1/03/1999; 20/01/2004).
} 
pero, como apuntamos más atrás, el mismo tiene que necesariamente complementarse conforme con los requerimientos de la teoría de la imputación objetiva. La forma sobre cómo la doctrina ha elaborado los diferentes criterios para esta solución, la estudiaremos inmediatamente.

\section{Determinación del engaño jurídico-penalmente relevante}

\section{1.- Teoría objetivo-subjetiva}

Debemos manifestar, previamente, en relación con este problema, que en la búsqueda del engaño penalmente relevante tanto la doctrina como la jurisprudencia comparada han seguido un arduo camino. ${ }^{31}$ Así, existen diversas posturas, como la objetivo-subjetiva ${ }^{32}$, otra que recurre a la teoría de la imputación

${ }^{30}$ No se olvide que la teoría de la condición tiene por base el hecho de que es causa del resultado «toda condición» que ha intervenido en su realización con indiferencia del cálculo de su proximidad temporal. Por ello, esta doctrina se conoce también con el nombre de «teoría de la equivalencia», ya que todas las condiciones del resultado se estiman como equivalentes. Buscar un comportamiento que ha condicionado causalmente un resultado se resuelve por medio del uso de la siguiente hipótesis: «es causal toda condición del resultado que, suprimida mentalmente, haría desaparecer el resultado». Para los seguidores de esta concepción establecer la causalidad como condición resulta suficiente para «afirmar la presencia del tipo objetivo» (Véase BERDUGO, 2004, p. 219 ss).

${ }^{31}$ Esta discusión debe circunscribirse a aquéllos países que no siguen el sistema alemán en materia de estafa. En efecto, en dicho país, el filtro normativo no se sitúa en el ámbito del engaño, sino en el perjuicio (con un amplio análisis, véase HERNÁNDEZ BASUALTO, 2003, p. 160 ss).

${ }^{32}$ En esta dirección, la jurisprudencia española ha señalado que se trata de un doble juicio, es decir, abstracto y concreto, explicando que, ante todo, considerada en abstracto, la maniobra engañosa ha de tener entidad para crear una apariencia de realidad y seriedad en el mundo entre personas de mediana perspicacia e inteligencia; y además, considerada en concreto, ha de valorarse la persona a la que se dirige el engaño, examinando si, en esas concretas circunstancias, el engaño es suficiente para mover su voluntad (Véase Sentencias del Tribunal Supremo español 4/05/1999; 9/06/1999; 20/03/2000; 24/09/2002; 5/05/2003; 27/06/2003; 26/06/2003; 24/07/2003; 20/01/2004; 2/04/2004; 17/05/2004; 15/02/2005). Asimismo, el Tribunal Supremo español ha concluido que, en relación con la preponderancia de un criterio mixto sobre el particular, consciente la doctrina y la jurisprudencia de la dificultad de esta cuestión, lo que se propone es un parámetro mixto, de forma que sobre una base objetiva de idoneidad general del artificio se tomen en consideración posteriormente las aptitudes y circunstancias del sujeto pasivo y las atinentes al medio social donde se producen los hechos. También, expresa que ni pueden ser desprotegidas penalmente las personas con una aptitud de diligencia inferior al término medio, ni puede entenderse incondicionalmente que el engaño es bastante porque en el caso concreto ha producido el error en el sujeto pasivo, pues, de ser así, todo engaño lo sería (Véase Sentencia del Tribunal Supremo español 6/05/2002). Finalmente, en este sentido, la jurisprudencia española se inclina por afirmar que existe entonces una «exigencia de proporcionalidad», que ha de ser suficiente y proporcionada para la consecución del fin propuesto, habiendo de tener adecuada entidad para que en la convivencia social actúe como estímulo eficaz del traspaso patrimonial. Asimismo, el Tribunal Supremo español ha manifestado que esa idoneidad se valora no sólo atendiendo a módulos objetivos, centrados en la apariencia de seriedad suficiente para convencer a personas de mediana perspicacia y diligencia, sino también a las condiciones personales de la víctima (Confróntese 
Balmaceda / Araya - Engaño en la estafa: ¿una puesta en escena?

objetiva $^{33}$ - a la que adherimos- y, por último, existe una renovada modalidad de la lesión de la veracidad ${ }^{34}$-que, con similares o diferentes criterios, también acude a la teoría de la imputación objetiva-.

Así las cosas, hace ya décadas que la doctrina española viene denunciando una amplitud enorme del engaño como elemento típico del delito de estafa, toda vez que se contenía una referencia analógica en el Código español que hablaba de "todo engaño" 35. Sin embargo, esta situación cambió en 1983, cuando se introdujo la exigencia en la estafa de que el engaño sea "bastante".

Sobre la exigencia de "bastante",37 que conlleva el engaño, la jurisprudencia española ha manifestado que este concepto no puede servir para desplazar en el

Sentencias del Tribunal Supremo español 30/10/1997; 7/11/1997; 4/02/1998; 24/03/1999; 20/07/1998; 28/01/1999; 4/05/1999; 16/07/1999; 6/03/2000; 1/03/2000; 29/01/2002; $9 / 06 / 2003 ; 16 / 07 / 2003 ; 22 / 10 / 2003 ; 1 / 03 / 2004)$. A su vez, la jurisprudencia chilena ha señalado que el engaño debe ser idóneo para inducir a error, lo que debe ser considerado objetivamente y, paralelamente, desde la perspectiva subjetiva, momento en el cual deben tomarse en cuenta las condiciones particulares del sujeto pasivo (Confróntese Sentencia de la Corte de Apelaciones de Rancagua 01/08/2008).

${ }_{33}$ Por todos, véase BAJO FERNÁNDEZ, 2004, p. 56 ss; BAJO FERNÁNDEZ, 2004-b, p. 268269; BAJO FERNÁNDEZ / PÉREZ MANZANO, 1993, p. 270 ss; GUTIÉRREZ FRANCÉS, 1991, p. 371 ss; TORÍO LÓPEZ, 1982, p. 883 ss; GÓMEZ BENÍTEZ, 1985, p. 338 ss; PÉREZ MANZANO, 1995, p. 285 ss; VALLE MUÑIZ, 1987, p. 52, 138, y, especialmente, 141 ss; QUINTERO OLIVARES, 2000, p. 54; CHOCLÁN MONTALVO, 2000, p. 79 ss; PASTOR MUÑOZ, 2004, p. 119 ss, 145 ss, y 167 ss; MAGALDI PATERNOSTRO, 2004, p. 746-747; ÁLVAREZ ÁLVAREZ, 2007, p. 559; ARROYO DE LAS HERAS, 2005, p. 36 ss; NAMER, 2002, p. 51 ss; FERNÁNDEZ DÍAZ, 2005, p. 186 ss; REBOLLO VARGAS, 2008, p. 442 ss.

${ }^{34}$ Debe admitirse, como punto de partida de este tema, que la «falta de verdad» o «inveracidad», no significa la falta de correspondencia entre lo que se piensa y lo que se dice o expresa (o sea, la «mentira»), sino que la falta de correspondencia entre la verdad y lo expresado (Confróntese PASTOR MUÑOZ, 2004, p. 55, y 263 ss).

${ }^{5}$ Véase ANTÓN ONECA, 1958, p. 61 ss; QUINTANO RIPOLLÉS, 1977, p. 589 ss. Al día de hoy, este sistema se mantiene en Chile (crítico, HERNÁNDEZ BASUALTO, 2003, p. 160 ss).

36 Art. 528 CP español, introducido por la LO. 8/1983, de 25 de Junio: «Cometen estafas los que con ánimo de lucro utilizan engaño bastante para producir error en otro, induciéndole a realizar un acto de disposición en perjuicio de sí mismo o de tercero. El reo de estafa será castigado con la pena de arresto mayor si la cuantía de lo defraudado excede de 30.000 pesetas. Si concurrieren dos o más circunstancias de las expresadas en el art. siguiente o una muy cualificada, la pena será de prisión menor. Si concurrieren las circunstancias primera o séptima con la octava, la pena será de prisión mayor. Si concurriere sólo alguna de las circunstancias del art. siguiente, la pena se impondrá en su grado máximo».

${ }^{37}$ De modo similar, el art. 159 ACP exige que el engaño sea suficiente, al decir: «El que con ánimo de lucro y mediante un engaño suficiente para provocar error en otro, obtenga que éste realice una disposición patrimonial con perjuicio propio o de tercero, será castigado con pena de reclusión menor en su grado mínimo a medio. La pena se podrá elevar en un grado cuando el hecho revista especial gravedad, en atención a la cuantía del perjuicio ocasionado o a los efectos especialmente perjudiciales que tenga para la víctima. Tratándose de perjuicios de ínfima cuantía, el tribunal podrá prescindir de la pena de reclusión e imponer en su lugar sólo la pena de multa de una a diez unidades tributarias mensuales». 
sujeto pasivo del delito todas las circunstancias concurrentes desplegadas por el ardid del autor del delito, de manera que termine siendo responsable de la maquinación precisamente quien es su víctima. Y, asimismo, afirma el Tribunal Supremo español que solamente el engaño burdo, esto es, aquel que puede apreciar cualquiera, impide la concurrencia del delito de estafa, porque, en ese caso, el engaño no es "bastante". Dicho de otra manera, el criterio jurisprudencial consiste en que el engaño no puede quedar neutralizado por una diligente actividad de la víctima, porque en caso contrario quedarían fuera del derecho penal aquellos comportamientos que aprovechan la debilidad convictiva de ciertas víctimas -los timos más populares-, o el traspaso de aquellos resortes que se fundamentan en el principio de confianza en el tráfico mercantil -generalmente, los llamados "negocios criminalizados"- -38 . A mayor abundamiento, el Tribunal Supremo español, para explicar el concepto de "engaño bastante", expresa, en primer lugar, que no todo engaño es típico, y que sólo lo es el que es bastante, es decir, el que sea capaz de traspasar lo ilícito civil y penetrar en la ilicitud penal, y además que sea idóneo, relevante y adecuado para producir el error que genera el fraude, capaz de mover la voluntad normal de una persona. ${ }^{39} \mathrm{E}$, igualmente, la jurisprudencia española manifiesta, con razón, que es difícil determinar para esto una norma de validez general, señalando que puede admitirse como idóneo y de normal eficacia cualquier engaño que consista en la falsa expresión de hechos o condiciones que se presenten a la generalidad de las personas como plausibles, razonables y creíbles, debiendo observarse para ello las circunstancias concretas de cada caso; ${ }^{40}$ afirmando que para estos términos, deben tenerse presente los siguientes criterios básicos:

(a) El engaño ha de entenderse bastante cuando haya producido sus efectos defraudadores, logrando el engañador, mediante el engaño, engrosar su patrimonio de manera ilícita, o lo que es lo mismo, es difícil considerar que el engaño no es bastante cuando se ha consumado la estafa; $;^{41} \mathrm{y}$,

(b) El engaño bastante, en principio, es aquél que es suficiente para provocar el error de otra persona al que va destinada, declarando que para la determinación de lo que deba entenderse por bastante es preciso tener en cuenta las condiciones del sujeto pasivo que recibe el engaño para el desapoderamiento de su patrimonio. ${ }^{42}$

De forma semejante -aunque menos exigente-, el sistema italiano exige en la estructura de la conducta típica de la estafa la existencia de "artificios" o

\footnotetext{
38 Confróntese Sentencia del Tribunal Supremo español 1/03/2004.

39 Véase Sentencias del Tribunal Supremo español 21/01/2002; 23/10/2002; 28/11/2002; 8/04/2003; 20/01/2004; 28/01/2004; 25/03/2004; 15/02/2005; 17/02/2005; GARCÍA RIVAS, 2005, p. 23; REBOLLO VARGAS, 2008, p. 440 ss.

${ }^{40}$ Confróntese Sentencias del Tribunal Supremo español 21/01/2002; 12/02/2004.

${ }^{41}$ Véase Sentencias del Tribunal Supremo español 24/04/2002; 12/02/2004.

${ }^{42}$ Véase Sentencia del Tribunal Supremo español 28/11/2002.
} 
Balmaceda / Araya - Engaño en la estafa: ¿una puesta en escena?

"insidias". Por artificio, se entiende la simulación o disimulación de la realidad apta para inducir en error a una persona a causa de la percepción de una falsa apariencia; en otras palabras, cada comportamiento efectuado aparentando lo que no existe, y que actúe sobre la realidad externa. Por insidia, por su parte, se entiende cada envolvimiento solapado de la psique ajena, apto para causar un error a través de una falsa apariencia, realizado por medio de un programa ingenioso de palabras destinado a persuadir y a orientar de modo desviante las representaciones y las decisiones ajenas. Finalmente, se dice que la diferencia entre los artificios y las insidias debería ser vista en el diferente grado de intensidad engañadora: la insidia, consistiendo en una maquinación solapada, causaría más fácilmente la inducción en error que con respecto del artificio, que solicitaría actos y palabras idóneas a transformar la realidad exterior.

Pues bien, es en este espinoso ámbito donde surge la concepción objetivosubjetiva para determinar qué es un engaño penalmente relevante, que exige algo parecido a una "puesta en escena" 44 (mise en scène del derecho francés) ${ }^{45}$ equivalente a lo que el modelo alemán denomina "acción concluyente" ${ }^{46}$. Sobre esta doctrina ${ }^{47}$

${ }^{43}$ Confróntese FANELLI, 1998, p. 29 ss; LUCARELLI, 2002, p. 11 ss; MAGGINI, 1988, p. 7 ss; PEDRAZZI, 1955, p. 177 ss; ZANNOTTI, 1993, p. 17 ss; ANTOLISEI, 2002, p. 353 ss; FIANDACA / MUSCO, 2005, p. 172 ss; MANTOVANI, 2002, p. 191 ss; PECORELLA, 2006, NM 4 ss.

${ }^{44}$ Esta es la doctrina absolutamente mayoritaria en Chile. Por todos, véase ETCHEBERRY, 1998, p. 394-395, y 407; BULLEMORE / MACKINNON, 2007, p. 73-74; GARRIDO MONTT, 2002, p. 323 ss. Así también, la jurisprudencia chilena, confróntese Sentencias de la Corte Suprema 17/07/2001; 21/03/1995; 17/07/2001; Sentencia de la Corte de Apelaciones Santiago 30/03/2007; y, las sentencias citadas por MERA / CASTRO, 2007, p. 256; y por SILVA SILVA, 2005, p. 353. En contra, por todos, MERA FIGUEROA, 2001, p. 58 ss, y 256 ss (aunque aceptándola para el art. 468 CP); POLITOFF / MATUS / RAMÍREZ, 2005, p. 431; HERNÁNDEZ BASUALTO, 2003, p. 160 ss; YUBERO, 1993, p. 99 ss; FERNÁNDEZ DÍAZ, 2005, p. 184 ss.

${ }^{45}$ Clásico partidario de esta doctrina es CARRARA, 1987, \2344, al exponer que para haber estafa se requiere algo «material», una especie de «aparato escénico». Señala también que hay que distinguir entre mentira y artificio. La mentira, en su opinión, no es delito, porque estima que nadie debe creer fácilmente en las palabras ajenas. En cambio el artificio sí lo sería, «cuando no tiende a una burla inocente sino a un injusto despojo». En la misma línea, ANTÓN ONECA, 1958, p. 61, afirma que la mentira no es delito porque no se debe creer fácilmente en las palabras de otros. Manifiesta que lo que la ley proscribe es una «maquinación», es decir, una mise en scène cuyo objetivo sea dar crédito a la mentira. Por último, partidario también de esta propuesta, BUSTOS RAMÍREZ, 1991, p. 190, agrega que el engaño supone un ardid, una determinada maquinación o simulación por parte del sujeto que implica que se requiera más que una simple mentira (Similar, MESTRE DELGADO, 2005, p. 281) En contra, por todos, MUÑOZ CONDE, 2007, p. 423; QUINTANO RIPOLLÉS, 1977, p. 596-597; VIVES ANTÓN / GONZÁLEZ CUSSAC, 1996, p. 1224; VIVES ANTÓN / GONZÁLEZ CUSSAC, 2004, p. 481; ROMERO, 2007, p. 121; VALLE MUÑIZ, 1987, p. 144-145.

46 Véase BAJO FERNÁNDEZ, 2004, p. 33; BAJO FERNÁNDEZ, 2004-b, p. 25-251; BAJO FERNÁNDEZ / PÉREZ MANZANO, 1993, p. 275.

47 Así, CRAMER / PERRON, 2006, NMs 14 ss; TIEDEMANN, 1999, NMs 28 ss, donde también dice que una acción concluyente se deduce a partir de una acción o del conjunto de las mismas que 
podemos decir que la misma existe cuando el autor no manifiesta expresamente el engaño pero lo declara con su comportamiento, siendo decisivo que el valor declarativo del mismo lo tiene la acción completa del autor según el punto de vista del tráfico jurídico, que debería determinarse mediante criterios objetivos respecto al tipo de negocios en el caso concreto. ${ }^{48}$

Así las cosas, para la concepción objetivo-subjetiva, debemos manifestar que el engaño se mide, en primer término, -como no podía ser de otra manera- de forma objetiva, ${ }^{49}$ exigiendo que la maniobra fraudulenta tenga un aspecto de seriedad y realidad suficiente para defraudar a personas de mediana perspicacia y diligencia (esta entidad del engaño es la que permite excluir del delito de estafa las hipótesis del pago a un curandero o brujo para obtener determinados fines) ${ }^{50}{ }^{51}$. No obstante, debido a que en la estafa se requiere por parte del engañado cierta credulidad, confianza y buena fe, la concepción en examen apunta que hay que completar este proceso con un módulo subjetivo que determine la idoneidad del engaño en función de las condiciones personales del sujeto pasivo ${ }^{52}$. Es decir, lo

integran el comportamiento del autor; BACIGALUPO, 1994, p. 187-189; BAJO FERNÁNDEZ, 2004-b, p. 2003; BACIGALUPO, 2007-b, p. 170.

48 Finalmente, sobre este problema es muy ilustrativo tener presente a VALLE MUÑIZ, 1986, p. 866-867, cuando señala que el silencio bajo determinados condicionamientos puede estimarse como una verdadera manifestación de voluntad, dando como ejemplo el de quien en un restaurante come y no paga, engaña, no por haber omitido su falta de dinero, sino porque el entrar en el lugar y pedir un cubierto daba a entender su capacidad y disposición al pago (siempre poniendo atención en los usos y sectores del tráfico).

49 Sobre esto, el Tribunal Supremo español ha afirmado que «objetivamente» debe ser valorado como bastante para producir error aquella maquinación engañosa que adopte apariencias de veracidad y de realidad creíble por la media de las personas (Confróntese Sentencias del Tribunal Supremo español 24/04/2002; 14/05/2002; 27/05/2002; 28/11/2002; 12/03/2003; 7/04/2003; 21/04/2003; 22/05/2003; 27/11/2003; 5/12/2003; 22/09/2004.

${ }^{50}$ La Sentencia del Tribunal Supremo español 2/02/2007 marca un hito fundamental. En efecto, señala que en el mundo intercomunicado del siglo XXI, únicamente en un supuesto realmente excepcional puede ser reprensible penalmente el supuesto engaño que comporta confiar en la quiromancia. Tras esta sentencia, las argucias basadas en apuestas irresponsables a los «supuestos poderes especiales» de los curanderos, asentadas en la superstición popular, pasan del plano de la represión penal a la civil. La sentencia llama más la atención si atendemos las circunstancias lastimosas en las que quedaron los engañados (abocados a la ruina y víctimas de enfermedades). En consecuencia, lo que en la resolución se considera de mayor protagonismo, más que las consecuencias del timo, es la entidad del engaño, contrastado con las circunstancias subjetivas del que sufrió el ardid y las objetivas de la sociedad en la que se produjo (con mayor detalle, véase GUDÍN RODRÍGUEZ-MAGARIÑOS, 2007, passim).

51 Así, GONZÁLEZ RUS, 1986, p. 265). En contra, VILA MAYO, 1984, p. 965 ss; VILA MAYO, 1988, p. 15 ss; VILA MAYO, 1991, p. 5790 ss, para quien, pese a aceptar un modelo objetivoindividual en la determinación del engaño, a éste lo considera como preeminentemente subjetivo, situándolo en el ámbito de la conducta comunicativa y, por ello, estima necesaria su proyección en las normas de la comunicación del lenguaje; también, QUINTANO RIPOLLÉS, 1977, p. 590.

${ }^{52}$ Así, el Tribunal Supremo español ha expresado que «subjetivamente» entran en juego el principio de la buena fe y las condiciones personales del sujeto engañado, que por su incultura, situación, edad o déficit intelectual, es más sugestionable, lo que significa que la condición de bastante se debe 
Balmaceda / Araya - Engaño en la estafa: ¿una puesta en escena?

que se trata de buscar en la idoneidad del engaño es si el error se ha debido al engaño o, por el contrario, a algún comportamiento negligente de la víctima, pues en estos últimos casos, estiman debe negarse la relación de causalidad y, por lo tanto, el carácter idóneo del engaño. ${ }^{53}$

En relación con estos problemas, -que interesan al trasnochado debate de la diferenciación entre el fraude civil y penal- ${ }^{54}$ creemos que al engaño se le ha dado un protagonismo exagerado, ya que, a fin de cuentas, el debate de la distinción de ilicitudes será, en definitiva, un problema de tipicidad ${ }^{55}$ que tendría que solucionarse conforme a los elementos hermenéuticos tradicionales y, como se sabe, los tipos penales tienen que cumplir un objetivo político-criminal determinado, que tendría que delimitarse conforme a una interpretación "teleológica". Dicho con otras palabras, al engaño se le ha otorgado un protagonismo desmedido, ya que no existe un engaño civil y otro penal, sino que "conductas engañosas que, por cumplir las exigencias típicas, devienen penalmente relevantes". ${ }^{56}$

Por estos motivos, pensamos que el problema debe resolverse conforme a los criterios de la teoría de la imputación objetiva, cuyos rasgos esenciales analizaremos a continuación.

\section{2.- Estafa e imputación objetiva}

En este trabajo, como ya se ha manifestado, se defiende una delimitación necesaria del engaño típico en sede de imputación objetiva, manifestándonos, en este sentido, contrarios a afirmar el rechazo a priori de un engaño típico a efectos del delito de estafa que no implique una puesta en escena. ${ }^{57}$

valorar intuito personae (Confróntese Sentencias del Tribunal Supremo español 24/04/2002; $14 / 05 / 2002 ; 27 / 05 / 2002 ; 28 / 11 / 2002 ; 12 / 03 / 2003 ; 7 / 04 / 2003 ; 21 / 04 / 2003 ; 22 / 05 / 2003$; $27 / 11 / 2003 ; 5 / 12 / 2003 ; 22 / 09 / 2004)$.

53 Para el estudio de esta postura, véase, BAJO FERNÁNDEZ, 2004, p. 35 ss; BAJO FERNÁNDEZ, 2004-b, p. 251 ss; BAJO FERNÁNDEZ / PÉREZ MANZANO, 1993, p. 275 ss; PÉREZ MANZANO, 1998, p. 443 ss; GONZÁLEZ RUS, 1986, p. 272-273; GONZÁLEZ RUS, 2005, p. 509; QUINTANO RIPOLLÉS, 1977, p. 590.

54 Ya en la segunda mitad del siglo XIX, ponía de manifiesto que este problema es arduo, y manifestaba que resultaba imposible una delimitación segura entre ambos ilícitos, GROIZARD GÓMEZ DE LA SERNA, 1897, p. 7 ss.

55 En el mismo sentido, VALLE MUÑIZ, 1987, p. 18, 40 y 75; GONZÁLEZ RUS, 1986, p. 288 ss; QUINTERO OLIVARES, 2000, p. 50 ss; BAJO FERNÁNDEZ, 2004, p. 70 ss; BAJO FERNÁNDEZ, 2004-b, p. 276; BAJO FERNÁNDEZ / PÉREZ MANZANO, 1993, p. 293-294; HERNÁNDEZ BASUALTO, 2003, p. 158; GARRIDO MONTT, 2002, p. 317-318.

56 Así, GUTIÉRREZ FRANCÉS, 1991, p. 342.

57 Así, por todos, MUÑOZ CONDE, 2007, p. 423; QUINTANO RIPOLLÉS, 1977, p. 596-597; VIVES ANTÓN / GONZÁLEZ CUSSAC, 1996, p. 1224; VIVES ANTÓN / GONZÁLEZ CUSSAC, 2004, p. 481; ROMERO, 2007, p. 121; VALLE MUÑIZ, 1987, p. 144-145; FERNÁNDEZ DÍAZ, 2005, p. 186 ss. 
Asimismo, -previamente- creemos que sobre este tema resulta sumamente relevante tener presente que el punto de vista desde el que se observe a la víctima cambia totalmente según se trate del juicio de imputación objetiva de la conducta o del resultado. En efecto, si se parte del primer juicio, debe tenerse como base un modelo de víctima para poder de esa manera construir la tipicidad desde un ámbito objetivo y, por esta razón, se tiene que dejar de lado las características de la víctima y del progreso causal. En cambio, en el juicio de imputación objetiva del resultado - que defendemos en este trabajo- son importantes las peculiaridades de la víctima: de hecho, debe ponerse atención en la víctima del caso concreto y en el proceso causal que realmente se originó. ${ }^{58}$

De esta manera, no existe entonces unanimidad en torno a lo que se entiende por «imputación objetiva», e inclusive todavía existen detractores de este juicio de imputación (sobre todo, desde la teoría final de la acción). Sin embargo, la doctrina española dominante entiende que el punto central de atención es el del juicio de imputación objetiva del resultado, tanto desde un punto de vista general como en relación al delito de estafa en particular, partiendo del siguiente supuesto: ${ }^{59}$ asegurada la relación de causalidad conforme con la teoría de la equivalencia de las condiciones, deben agregarse criterios correctores de índole normativo que exigen la ejecución de un peligro por parte del autor y, que el mismo, no se encuentre cubierto por un riesgo permitido dentro del alcance del tipo.

Hemos dicho varias veces que la estafa, en cuanto delito de resultado, debe ser analizada conforme propugna la teoría de la imputación objetiva, y esto se debe, por ejemplo, a que las mismas deficiencias imputadas a las teorías causales en el ámbito del homicidio pueden ser objetadas en el ámbito de la estafa. ${ }^{60}$ En este sentido, como delito de resultado, la estafa presenta características especiales que han de tenerse en cuenta al efectuar su examen de imputación objetiva. ${ }^{61}$ De una

\footnotetext{
58 Véase PASTOR MUÑOZ, 2004, p. 147.

59 Confróntese MARTÍNEZ ESCAMILLA, 1992, p. 41 ss, 125 ss, 172 ss, 265 ss; PASTOR MUÑOZ, 2004, p. 152, e ibídem, nota 30; ROXIN, 1997, p. 342 ss; MIR PUIG, 2006, p. 357 ss; MIR PUIG, 2005, p. 240 ss.

60 Véase PÉREZ MANZANO, 1995, p. 285-286.

${ }^{61}$ Así, el Tribunal Supremo español ha dicho, sobre la aplicación de la teoría de la imputación objetiva en el delito de estafa, en general, que en el mismo no basta para realizar el tipo objetivo con la concurrencia de un engaño que causalmente produzca un perjuicio patrimonial al titular del patrimonio perjudicado, sino que es necesario todavía, en un plano normativo y no meramente ontológico, que el perjuicio patrimonial sea imputable objetivamente a la acción engañosa, de acuerdo con el fin de protección de la norma, requiriéndose a tal efecto en el art. 248 CP que ello tenga lugar mediante un engaño «bastante». Por tanto, sostiene que el contexto teórico adecuado para resolver los problemas a que da lugar esta exigencia típica es el de la imputación objetiva del resultado (Confróntese Sentencia del Tribunal Supremo español 15/02/2005). A su vez, la jurisprudencia chilena, en un fallo reciente, ha manifestado que el engaño típico requiere haber generado un riesgo idóneo o típicamente relevante (analizado ex ante y conforme al hombre medio), al bien jurídico propiedad, imputable objetivamente al actuar doloso del sujeto activo (Confróntese Sentencia del Segundo Tribunal de Juicio Oral en lo Penal de Santiago 16/05/08).
} 
Balmaceda / Araya - Engaño en la estafa: ¿una puesta en escena?

parte, el proceso causal que fundará la producción del perjuicio económico aparece típicamente dispuesto en sus hitos cardinales, ${ }^{62} \mathrm{y}$, de otro lado, es un delito que demanda la participación de la víctima en el transcurso ejecutivo. ${ }^{63}$

En relación con este problema, podemos decir que de estas ideas pueden desprenderse las siguientes consecuencias:

(a) Los hitos fundamentales del proceso causal del delito de estafa son: de un lado, la preparación del proceso causal que convergerá en el perjuicio económico que únicamente puede originarse por engaño. De otra parte, algunas legislaciones representan explícitamente no sólo la acción y el resultado, sino que insinúan otro eslabón intermedio de la cadena: el acto de disposición patrimonial. ${ }^{64}$ Ello significa que éste pueda ser examinado como resultado del engaño y como condición del perjuicio; ${ }^{65} \mathrm{y}$,

(b) La existencia del acto de disposición muda a la estafa en lo que la doctrina designa como "delito de relación", de forma que para el estudio de la imputación objetiva del resultado no sólo tendrán que examinarse las características del comportamiento del autor -el engaño-, sino también las que posea la participación de la víctima - el acto de disposición realizado por error-. Esto concebirá como substancialmente relevante el estudio del fin de protección de la norma en el delito de estafa. ${ }^{67}$

\footnotetext{
${ }^{62}$ Confróntese LÓPEZ BARJA DE QUIROGA, 1990, p. 219 ss.

${ }^{63}$ En efecto, en relación con esto, la jurisprudencia española señala que si el sujeto activo conoce la debilidad de la víctima y su escaso nivel de instrucción, aquellos engaños que en términos de normalidad social aparecen como objetivamente inidóneos, sin embargo, en atención a la situación del caso particular, aprovechada por el autor, el tipo de la estafa no puede ser excluido. También, manifiesta que cuando el autor busca de propósito la debilidad de la víctima y su credibilidad por encima de la media, en su caso, es insuficiente el criterio de la inadecuación del engaño según su juicio de prognosis basado en la normalidad del suceder social, pues el juicio de adecuación depende de los conocimientos especiales del autor. Por ello, ha terminado por imponerse lo que se ha llamado módulo objetivo-subjetivo, que en opinión del Tribunal Supremo español, en realidad, es preponderantemente subjetivo (Confróntese Sentencia del Tribunal Supremo español 15/02/2005).

${ }^{64}$ Expresamente se menciona este elemento en los arts. 248.1 CP español y 159 ACP. No sucede lo mismo en los arts. 640 CP italiano, 468 y 473 CP chileno, ni en el $\int 263$ StGB. No obstante, en estos últimos países se estima como elemento esencial, como «elemento no escrito» (Así, véase, en Alemania, WESSELS / HILLEMKAMP, 2007, \13, NMs 514 ss; CRAMER / PERRON, 2006, NM 54; en Italia, FIANDACA / MUSCO, 2005, p. 170, y 178 ss; en Chile, POLITOFF / MATUS / RAMÍREZ, 2005, p. 418 y 433-434).

${ }^{65}$ Así, PÉREZ MANZANO, 1995, p. 290 ss.

${ }^{66}$ Véase PÉREZ MANZANO, 1995, p. 292; MAGALDI PATERNOSTRO, 2004, p. 742 y 748; CODERCH / SILVA SÁNCHEZ, 1999, p. 99; PASTOR MUÑOZ, 2004, p. 265.

${ }^{67}$ Así, desde antiguo se viene comprendiendo al delito de estafa, para diferenciarlo del resto de delitos contra el patrimonio, como un delito que se caracteriza por constatarse una cooperación de la víctima del engaño (como hacen, por ejemplo, QUINTANO RIPOLLÉS, 1977, p. 640 ss; GONZÁLEZ RUS, 1986, p. 296-297; GONZÁLEZ RUS, 2005, p. 513).
} 
En este sentido, el Tribunal Supremo español ha manifestado que, como último estadio de la imputación objetiva, adquiere especial relevancia en el tipo de la estafa el alcance de la protección de la norma, que afirma constituye un criterio fundamental para delimitar el ámbito típico de la estafa y llevar a sus justos términos el principio de la función de protección subsidiaria que corresponde al derecho penal. ${ }^{68}$ Asimismo, ha manifestado que de acuerdo con el criterio del fin de protección de la norma, no constituye fin del tipo de la estafa evitar las lesiones patrimoniales fácilmente evitables por el titular del patrimonio que, con una mínima diligencia, hubiera evitado el menoscabo, pues como el tipo penal cumple sólo una función subsidiaria de protección y, un medio menos gravoso que el recurso a la pena es, sin duda, la autotutela del titular del bien; ${ }^{69}$ por último, el Tribunal Supremo español afirma que no basta para realizar el tipo objetivo con la concurrencia de un engaño que causalmente produzca un perjuicio patrimonial al titular del patrimonio perjudicado, sino que es necesario todavía, en un plano normativo y no meramente ontológico, que el perjuicio patrimonial sea imputable objetivamente a la acción engañosa, de acuerdo con el fin de protección de la norma, requiriéndose que ello tenga lugar mediante un engaño "bastante"

En este contexto, en conclusión, al engaño lo concebimos como aquella conducta - cualquiera - que crea un riesgo tipicamente relevante, para cuya idoneidad objetiva bastaría con que el mismo genere un riesgo típicamente relevante de producción de un acto de disposición por error que desemboque en un perjuicio patrimonial ${ }^{1}$.

Así, conforme con lo que hemos apuntado, la determinación de la tipicidad del engaño requiere una valoración de su capacidad para provocar un error y estimular el acto de disposición patrimonial, acorde con la tesis de la adecuación, de donde se concluye que se maniobra en este lugar con una doble medida, objetiva y subjetiva, de forma similar a como se concibe el deber de cuidado en los delitos imprudentes. Esta forma de proceder debe renunciarse, y ser suplantada por el juicio de pronóstico posterior objetivo, conforme al cual se enjuicia, según la doctrina española mayoritaria ${ }^{72}$, la idoneidad objetiva de una conducta para originar un determinado resultado.

\footnotetext{
${ }^{68}$ Confróntese Sentencia del Tribunal Supremo español 15/02/2005.

${ }^{69}$ Véase Sentencia del Tribunal Supremo español 15/02/2005.

${ }^{70}$ Confróntese Sentencia del Tribunal Supremo español 2/11/2004.

${ }^{71}$ Véase PÉREZ MANZANO, 1995, p. 299.

72 En esta dirección, véase VALLE MUÑIZ, 1987, p. 164 ss, lugar en que explica al juicio de adecuación del engaño como primer elemento de la imputación objetiva del delito de estafa, sosteniendo la exigencia de no perder de vista las circunstancias verdaderas y específicas del engañado y, afirmando también, la idoneidad del engaño cuando el autor logra obtener el resultado en virtud de conocimientos individuales que le posibilitan un dominio especial del hecho. No obstante, tenemos que apuntar que el autor no es del todo claro, pues parece que las peculiaridades de la víctima tienen autonomía en el juicio de adecuación, separadamente del conocimiento que de ellas tenga o pudiera poseer el autor. Asimismo, ubica equivocadamente al principio de autorresponsabilidad, pues el mismo no incide en el juicio de adecuación, sino en la relación de
} 
Balmaceda / Araya - Engaño en la estafa: ¿una puesta en escena?

Asimismo, conforme a un importante sector de la doctrina española, ${ }^{73}$ habrá que efectuar un juicio en relación con la probabilidad de que el engaño -la falta de verdad en lo que se dice o se hace con o sin puesta en escena-, estimado ex ante, origine un acto de disposición por error, basándose en las circunstancias conocidas o identificables por el hombre prudente en la órbita social del autor más los accidentes conocidos o reconocibles por el autor con base en sus conocimientos específicos, lo que no nos parece correcto, como veremos.

De esta forma, si una mentira es objetivamente idónea, ex ante considerada, para inducir a error estribará, de un lado, de que una alta cifra de contingencias provocaría un error a un hombre medianamente prudente. ${ }^{74}$ Sin embargo, la doctrina mantiene que hay que perfeccionar el modelo objetivo con uno subjetivo que establezca la idoneidad del engaño en función de las condiciones personales del engañado. ${ }^{75}$

En relación con este problema, quienes sigan la línea de Pérez Manzano ${ }^{76}$ estimarían que esto no es completamente correcto, por tanto las circunstancias de la víctima únicamente podrían ser asumidas en el juicio de adecuación si son conocidas o identificables por el autor del engaño (y así, en los supuestos combatidos habitualmente del niño o el débil mental, se aseverará la idoneidad del engaño si son accidentes indagados y revisables por el autor, lo que sucederá en la mayor parte de los casos) $)^{77}$.

A continuación, se constata también la circunstancia de que en el delito de estafa es vital el papel de la víctima titular de ciertos deberes de autoprotección. Incluso, se ha llegado a afirmar que el delito de estafa es un delito de "autolesión o de autoría mediata", utilizando como base el principio de "autorresponsabilidad" de la víctima. ${ }^{78}$ Es decir, se trata de averiguar si la participación de la víctima -de vital

riesgo y en lo que él denomina «esfera de protección de la norma en el tipo de estafa» (Véase PÉREZ MANZANO, 1995, p. 297, nota 46).

73 Así, PÉREZ MANZANO, 1995, p. 293 ss, y 302 ss.

${ }^{74}$ Así, aunque sin utilizar la terminología de la imputación objetiva, analizan el engaño conforme a parámetros semejantes, RODRÍGUEZ DEVESA / SERRANO GÓMEZ, 1995, p. 507, señalando: «En esta relación de adecuación han de tenerse en cuenta las circunstancias todas del caso concreto, entre ellas muy especialmente las que aprovecha o artificialmente crea el estafador para que el engaño encuentre un terreno abonado por la credulidad, v. gr., en relaciones anteriores sostenidas con el estafado».

75 Por todos, véase VIVES ANTÓN / GONZÁLEZ CUSSAC, 1996, p. 1220 ss; VIVES ANTÓN / GONZÁLEZ CUSSAC, 2004, p. 480 ss; LÓPEZ BARJA DE QUIROGA, 1990, p. 223; BAJO FERNÁNDEZ, 2004, p. 33 ss; BAJO FERNÁNDEZ, 2004-b, p. 250 ss.

76 PÉREZ MANZANO, 1995, p. 293, nota 29, y p. 297.

${ }^{77}$ En la misma dirección, TORÍO LÓPEZ, 1982, p. 884.

${ }^{78}$ En este sentido, KINDHÄUSER, 2002, p. 83 ss. 
importancia en el delito de estafa- distorsiona o no los criterios de imputación del error, o finalmente del perjuicio, a la conducta de engaño. ${ }^{79}$

Según lo que hemos afirmado poco más atrás, no creemos -como lo hace un sector de la doctrina española ${ }^{80}$ que el engaño, desde este punto de vista, será bastante -idóneo- para producir el error, cuando, examinado ex ante desde la perspectiva de un tercero imparcial, el comportamiento y sus circunstancias - especialmente los deberes de autoprotección que incumben a la víctimasupongan el riesgo que después se concreta en el resultado. Si bien es cierto que, de esta forma, se termina con el problema de la postura tradicional que, partiendo de un examen ex post de la relación engaño-error, casi siempre termina afirmando dicha relación de causalidad, pensamos que debería exigirse un requerimiento adicional: el fin de protección de la norma. ${ }^{81}$ Por ello, el error no debería incluirse en el engaño, ya que conllevaría el absurdo de desvalorar en el tipo el comportamiento sólo en función de la diligencia de la víctima, su credibilidad, o educación. Entonces, la aptitud para generar el error determinará no la existencia del engaño, sino, en su caso, su "relevancia" jurídico penal. ${ }^{82}$ En este sentido, el camino que nos parece más convincente será determinar el ámbito de protección del tipo de estafa, es decir, tendremos que orientar la función protectora de la estafa desde el bien jurídico tutelado, ${ }^{83}$ donde se plantea el conflicto del significado de la conducta de la víctima para la delimitación del alcance del tipo delictivo (así, en este lugar nos parece que no debería exigirse a la víctima la conducta de un héroe o santo, sino que una exigencia mínima dirigida a la autodefensa, cuando sea fácil de evitar el engaño por medio de una cómoda conducta dirigida a evitar la lesión del bien jurídico) ${ }^{84}$

Dicho con otras palabras, -para concluir y reafirmando lo que ya hemos manifestado- estimamos que para buscar si un riesgo cae o no dentro del ámbito del fin de protección de la norma, ${ }^{85}$ debería ponerse atención en los deberes de autoprotección de la víctima, los que dependen de las pautas sociales en el caso concreto y de las relaciones que existen entre el sujeto activo y el perjudicado (como la capacidad y acceso a las posibilidades de autoprotección, la existencia o no de una relación de confianza, su debilidad o fortaleza, etc.), ${ }^{86}$ es decir, en relación al relevante problema del engaño y su relación con el riesgo permitido, ya

\footnotetext{
79 Así, GONZÁLEZ RUS, 2005, p. 510-511.

${ }^{80}$ Véase PÉREZ MANZANO, 1995, p. 293 ss, y 302 ss.

${ }^{81}$ En esta dirección, TORÍO LÓPEZ, 1982, p. 883 ss; VALLE MUÑIZ, 1987, p. 163 y 168-169; CHOCLÁN MONTALVO, 2000, p. 85 y 94.

82 Así, GUTIÉRREZ FRANCÉS, 1991, p. 343-344.

${ }^{83}$ Confróntese VALLE MUÑIZ, 1987, p. 171.

${ }^{84}$ De esta manera, corresponde al intérprete determinar en qué casos el engañado merece el amparo de acuerdo con el sentido del tipo penal y cuándo deben desterrarse del ámbito de lo punible los comportamientos frente a los cuales el sujeto pasivo puede fácilmente protegerse a sí mismo y en forma razonable (Véase CHOCLÁN MONTALVO, 2000, p. 108, 111 y 116).

85 Así, CHOCLÁN MONTALVO, 2000, p. 120 ss.

${ }^{86}$ Confróntese CHOCLÁN MONTALVO, 2000, p. 259 ss.
} 
Balmaceda / Araya - Engaño en la estafa: ¿una puesta en escena?

se ha expresado que para afirmar la tipicidad del engaño se requeriría que el riesgo creado o incrementado de producir error e inducir al acto de disposición debería constituir un riesgo no permitido.

Por otra parte, respecto al problema de si son viables o no como forma de engaño los juicios de valor, un sector estima que, al contrario de lo que sucede en el derecho alemán, no lo impediría el derecho español vigente. ${ }^{87}$ Según otros, habrá que someter también los juicios de valor al juicio de adecuación, y, por tanto, tienen que analizarse las circunstancias del caso y el conocimiento que de ellas tenga o debiera tener el autor, ${ }^{88} \mathrm{y}$, para otro importante sector de la doctrina española, en principio no pueden constituir una modalidad de engaño, salvo cuando se sitúen fuera de la órbita de una mera "opinión", pues en esos casos se estaría presuponiendo falsamente la existencia de unos hechos, circunstancia que implicaría un incremento del riesgo permitido ${ }^{89}$-nuestro parecer lo desarrollaremos un poco más abajo- .

De otro lado, problemática resulta la relación existente entre el engaño y la estafa por omisión. ${ }^{90}$ Tradicionalmente discute la doctrina comparada si se puede engañar mediante una conducta omisiva, de manera que pueda considerarse típica a efectos del delito de estafa.

La jurisprudencia española se inclina por aceptar estas hipótesis cuando expone que el engaño no sólo existe cuando se desarrolla una puesta en escena destinada a crear una apariencia de solvencia que en realidad no existe, sino también cuando se omiten o escamotean elementos de la realidad cuyo conocimiento hubiera sido decisivo para disuadir a la otra parte de llevar a cabo un

\footnotetext{
87 A favor, por todos, ANTÓN ONECA, 1958, p. 61; GÓMEZ BENíTEZ, 1985, p. 343. En Chile, FERNÁNDEZ DÍAZ, 2005, p. 190, señalando que no existe ningún dato en la legislación chilena (equiparándola a la italiana y española) que lleve a excluir del ámbito del engaño típico a efectos de la estafa, a los engaños consistentes en valoraciones.

${ }^{88}$ En esta dirección, GÓMEZ BENÍTEZ, 1985, p. 343; PÉREZ MANZANO, 1995, p. 298.

${ }^{89}$ Así, BAJO FERNÁNDEZ, 2004, p. 43; BAJO FERNÁNDEZ, 2004-b, p. 257.

90 A favor, por todos, véase TIEDEMANN, 1999, NMs 51 ss; GÓMEZ BENÍTEZ, 1985, p. 343 ss; GONZÁLEZ RUS, 2005, p. 511; ROMERO, 2007, p. 124-125; PÉREZ DEL VALLE, 2005, p. 207 ss; ANTÓN ONECA, 1958, p. 64-65; RODRÍGUEZ DEVESA / SERRANO GÓMEZ, 1995, p. 502; MUÑOZ CONDE, 2007, p. 424; SUÁREZ GONZÁLEZ, 1997, p. 709; CALDERÓN / CHOCLÁN, 2005, p. 230; QUERALT JIMÉNEZ, 2008, p. 456; ETCHEBERRY, 1998, p. 392 y 397; GARRIDO MONTT, 2002, p. 322; POLITOFF / MATUS / RAMÍREZ, 2005, p. 425; HERNÁNDEZ BASUALTO, 2003, p. 166, quien acepta únicamente como fuentes de la posición de garante a la ley y el contrato, señalando que debe excluirse como tal a la buena fe, aunque tenga reconocimiento legal. En contra, por todos, confróntese QUINTANO RIPOLLÉS, 1977, p. 600; VALLE MUÑIZ, 1987, p. 172 ss; VALLE MUÑIZ, 1986, p. 863 ss; MAGALDI PATERNOSTRO, 2004, p. 449 ss; SALVADOR SALVADOR CODERCH / SILVA SÁNCHEZ, 1999, p. 106 ss; YUBERO, 1993, p. 120 ss; declarando que es muy difícil constatarla, reduciéndola al ámbito civil, véase BAJO FERNÁNDEZ, 2004, p. 42-43; BAJO FERNÁNDEZ, 2004-b, p. 256; BAJO FERNÁNDEZ / PÉREZ MANZANO, 1993, p. 280 ss.
} 
determinado contrato. ${ }^{91}$ En el mismo sentido, el Tribunal Supremo español ha dicho que la trama engañosa no sólo puede construirse sobre actuaciones positivas, encaminadas a formar una apariencia de realidad, que se ofrezca como cebo a los que se intenta defraudar, sino que también se presenta como elemento determinante de la estafa en los supuestos en los que, sin haber una actividad idónea para montar un escenario aparente, nos encontramos con una actitud omisiva o de ocultación de situaciones reales que, si hubieran sido conocidas por las personas a las que va dirigido el ardid, hubieran impedido que éstas hicieran el acto de disposición de su patrimonio propio o cuya administración y disponibilidad ejercía. ${ }^{92}$ Asimismo, la jurisprudencia en España manifiesta que hay engaño por omisión cuando la ocultación de datos significativos constituye el motor decisivo para que la parte desinformada acceda a realizar o autorizar la prestación y el consiguiente desplazamiento patrimonial. ${ }^{93}$ Por último, también ha dicho el Tribunal Supremo español que se da un engaño omisivo cuando al autor del hecho le afecta la obligación, consecuencia de la buena fe contractual, de poner de manifiesto a la otra parte contratante una información, deber de información que, por ejemplo, es trasgredido al ocultar datos significativos y decisivos en la compraventa de una vivienda que hicieron que la parte desinformada accediera a realizar el negocio jurídico con el consiguiente desplazamiento patrimonial y, que de otro modo, no hubiera celebrado. ${ }^{44}$

Sobre estos temas (omisión y juicios de valor), a nuestro entender, creemos que cualquier comportamiento podría constituir un engaño típico, siempre y cuando satisfaga las necesidades de imputación objetiva, es decir, que sea idóneo para producir error - no que produzca un estado de error "efectivo" ", o sea, dependerá de la admisión o no del estado de error como exigencia típica, y si cabe o no dentro de la esfera de protección de la norma. En este sentido, el engaño puede producirse a través del habla o por medios escritos, por medio de conductas positivas, e incluso a través de gestos. ${ }^{96}$

Pero, más allá de estas dificultades, -en el supuesto que se superen-, lo realmente problemático en la práctica del delito de estafa será el establecimiento de

\footnotetext{
91 Véase Sentencias del Tribunal Supremo español 26/02/1999; 18/01/2001; 29/07/2002; GARCÍA RIVAS, 2005, p. 22 ss. La jurisprudencia chilena ha aceptado que se puede engañar mediante una conducta omisiva para el caso del artículo 473 CP (estafa residual) (Véase Sentencia de la Corte de Apelaciones de Iquique 27/17/2007).

${ }^{92}$ Confróntese Sentencia del Tribunal Supremo español 13/05/2003.

93 Véase Sentencia del Tribunal Supremo español 2/12/2003; 28/01/2004.

${ }^{94}$ Confróntese Sentencia del Tribunal Supremo español 23/02/2004.

95 Así, GÓMEZ BENÍTEZ, 1985, p. 333 ss.

${ }^{96}$ Sobre el particular, nos parece que no cabe formular juicios generales a priori, ya que a fin de cuentas, el desarrollo de la teoría del delito determinará, finalmente, lo que es o no penalmente relevante (de manera similar, pero en relación con los juicios de valor, GUTIÉRREZ FRANCÉS, 1991, p. 345-346).
} 
Balmaceda / Araya - Engaño en la estafa: ¿una puesta en escena?

la posición de garante de la que debe surgir el deber de información frente a la víctima. $^{97}$

Debe hacerse presente que si se estima a la estafa como maquinación (mise en scène), habría que rechazar su posibilidad omisiva y en forma de juicio de valor. Asimismo, y como regla general, en España se observa la tendencia a admitir el engaño en el caso de los comportamientos concluyentes -como hemos visto, aquellos casos en que de forma tácita se lleva consigo la afirmación falsa de un hecho- ${ }^{98}$ y quienes rechazan los demás casos de omisión sostienen que son relegados al ámbito civil. ${ }^{99}$ Por último, se reconocería la comisión por omisión cuando el sujeto tuviese el deber jurídico de informar y no lo hace. ${ }^{100}$

A esta altura del debate, pensamos que debería afirmarse que el engaño aisladamente considerado no aporta criterio alguno para juzgar lo típico y lo atípico. En este sentido, lo relevante no será el engaño, ni tampoco el engaño "bastante", sino el "engaño bastante para producir error en otro", el que deberá examinarse, como se ba defendido, de acuerdo a los filtros de la teoría de la imputación objetiva. ${ }^{101}$

En conclusión, y siguiendo a Gómez Benítez, ${ }^{102}$ a los efectos de la tipicidad de la estafa, el engaño es "toda aquella conducta tendente a generar error en otra persona, realizada con fines defraudatorios, e idónea para conseguirlo". Como se puede deducir de lo que hemos manifestado, nos encontramos frente a un tipo legal susceptible de recibir múltiples lecturas y, por ello, lo que signifique la creación de un riesgo desaprobado o el incremento del riesgo permitido, y lo que diga relación con el ámbito de protección de la norma, será un problema que, al

\footnotetext{
${ }^{97}$ Nos parece que de forma general, se imponen en la doctrina las fuentes tradicionales de la ley $-\mathrm{O}$ reglamentaciones en general- y el contrato. Más problemático parece efectuar una hipótesis de injerencia, por ejemplo, basada en la participación en el mercado, lo que redundaría en equiparar sin más la calidad de comerciante con la de garante. Asimismo, alguna vez se ha propuesto el principio de la buena fe como fuente de posición de garante, pero se lo ha estimado demasiado genérico y vago (sobre este problema, véase TIEDEMANN, 1999, NMs 66 ss; PÉREZ DEL VALLE, 2005, p. $211 \mathrm{ss}$, y $217 \mathrm{ss})$.

98 Sobre el particular, el Tribunal Supremo español afirma que el engaño puede ser manifiesto o concluyente, y que existe engaño cuando el autor realiza una acción que por su significación social (acción concluyente) implica la afirmación de circunstancias que son relevantes para la decisión de la disposición patrimonial de la otra parte (confróntese Sentencia del Tribunal Supremo español 21/10/1998). Asimismo, ha señalado que el engaño puede tener lugar no sólo a través de una acción manifiesta, sino también por medio de una acción concluyente, es decir, cuando el autor se comporta según determinados usos sociales y comerciales que implican una afirmación de ciertas circunstancias (Véase Sentencia del Tribunal Supremo español 3/06/2003).

99 Así, por todos, BAJO FERNÁNDEZ, 2004, p. 73 ss; BAJO FERNÁNDEZ, 2004-b, p. 279 ss; BAJO FERNÁNDEZ / PÉREZ MANZANO, 1993, p. 280 ss.

100 Véase VIVES ANTÓN / GONZÁLEZ CUSSAC, 1996, p. 1218 ss; VIVES ANTÓN / GONZÁLEZ CUSSAC, 2004, p. 478-479.

101 Así, GUTIÉRREZ FRANCÉS, 1991, p. 350-352. Similar, GARCÍA RIVAS, 2005, p. 31 ss.

102 GÓMEZ BENÍTEZ, 1985, p. 338.
} 
final, se encontrará en manos del intérprete. Así, se excluyen de la tipicidad los engaños que generen un peligro jurídicamente irrelevante y aquellos que no incrementen el riesgo inexistente, por ejemplo, cuando nos encontramos frente a exageraciones comunes, inexactitudes socialmente toleradas, o cuando se empleen tópicos habituales en la publicidad. Y para terminar, en relación con la esfera de protección de la norma, algunos autores sostienen que parece dudoso que pueda aportar algo en la estafa, ${ }^{103}$ opinión que, como se afirmó más atrás, no compartimos, pues pensamos que es precisamente el filtro normativo que requiere la estafa para lo que consideramos su correcto tratamiento político-criminal.

\section{3.- Estafa como lesión de un derecho a la verdad}

Desde un punto de vista más moderno -que no seguimos, como veremos-, se pone atención al hecho de que el engaño constituye la lesión de un derecho a la verdad, o la infracción de un "deber de veracidad", es decir, desde esta posición, se cree que la estafa trata de garantizar un mínimo de verdad en la estructura normativa mercantil. ${ }^{104}$

Se afirma, a partir de esta concepción, que el engaño para ser penalmente relevante requiere que se haya incumplido el deber de veracidad, que se fija de acuerdo con dos criterios: ${ }^{105}$ un estándar que proviene de la posición de ambos sujetos, y el otro que emana de las conductas de los sujetos que reconceptualicen los deberes de fidelidad iniciales. De esta manera, sin acudir al nexo causal -que se estima trasnochado-, se dan respuestas efectivas a las hipótesis en que el engañado infringe sus deberes de autoprotección, o cuando es estructuralmente más débil.

Finalmente, podemos decir que esta postura repite con insistencia que el derecho a la verdad no es el bien jurídico protegido en el delito de estafa, y no se libra de la necesidad de una "doble medida", como sucede con la teoría tradicional dominante en España. ${ }^{106}$

\section{4.- $\quad$ Conclusiones}

$1^{\text {a }}$ Al engaño se le ha dado un protagonismo extremo, ya que el debate de la distinción de ilicitudes - penal y civil- al parecer será, en definitiva, un problema

\footnotetext{
${ }^{103}$ En este sentido, GUTIÉRREZ FRANCÉS, 1991, p. 389.

104 En esta dirección, por todos, KINDHÄUSER, 2002, p. 83 ss; PASTOR MUÑOZ, 2004, p. 167 ss; PASTOR MUÑOZ, 2006, p. 213 ss; PASTOR MUÑOZ, 2003, p. 453 ss; SALVADOR CODERCH / SILVA SÁNCHEZ, 1999, p. 75 ss; MAGALDI PATERNOSTRO, 2004, p. 741742, y 749; BACIGALUPO, 2007, p. 2000; BACIGALUPO, 2007-b, p. 166; PIÑA ROCHEFORT, 2006, p. 47 ss.

105 Confróntese, por todos, PASTOR MUÑOZ, 2004, p. 168, y 217 ss; PASTOR MUÑOZ, 2006, p. 213-214; PASTOR MUÑOZ, 2003, p. 461 ss; SALVADOR CODERCH / SILVA SÁNCHEZ, 1999, p. 98 ss, 112 ss, y passim; PIÑA ROCHEFORT, 2006, p. 70 ss.

106 Véase BAJO FERNÁNDEZ, 2004, p. 42; BAJO FERNÁNDEZ, 2004-b, p. 256.
} 
de tipicidad que tendría que remediarse de acuerdo a los elementos hermenéuticos tradicionales.

$2^{2}$. El derecho chileno no contiene una definición general del delito de estafa clásico. Esto es fundamental para asumir una postura sobre el problema.

$3^{a}$. Nos parece lógico que conforme a nuestra idiosincrasia en la determinación de lo que es un "engaño típico" el filtro normativo de este hecho punible se sitúe en el engaño y no en el perjuicio. No obstante, ¿Por qué la mayoría de la doctrina insiste en utilizar la doctrina de la mise en scène? Creemos que la ley no exige utilizar este sistema. En efecto, en nuestro concepto el derecho chileno exige una delimitación, pero este procedimiento tiene que adecuarse a los tiempos, y por ello tiene que tratarse de un sistema normativo, y el sistema más coherente a estos efectos es el de la teoría de la imputación objetiva del resultado.

$4^{a}$. La mayoría de la doctrina chilena sostiene que el engaño en la estafa implicaría una "relación directa" entre dos personas. Frente a este planteamiento, ¿no debería revisarse el concepto de engaño?, toda vez que gracias al sistema chileno sobre el delito de estafa (que no contiene una definición general del delito), y ante el actual sistema de relaciones jurídico-penal-económicas, ¿no sería el engaño un elemento sumamente cambiante que dependa del ingenio humano?

$5^{a}$. En este sentido, sabemos que el engaño se configura a través de una interpretación, y esto es obligado en un sistema de la estafa, como es el chileno. Entonces, ¿acaso no será relevante tener a la vista la realidad social de la época en que corresponda la aplicación del engaño?

$6^{a}$. Esto es esencial, ya que el propio fundamento que contiene el sistema de la mise en scène consiste en atender a la realidad social del país, para poderse limitar al engaño típico. Dicho de otra manera, mientras más exigente sea el filtro normativo al nivel del engaño es porque la realidad social no permite otra solución. No obstante, tratándose de un sistema de control social, ¿no debería tratarse de un sistema que otorgue soluciones efectivas a la realidad jurídico-social contemporánea?

$7^{a}$. Por estos motivos defendemos una delimitación necesaria del engaño típico en sede de imputación objetiva, declarándonos, en este sentido, contrarios a afirmar el rechazo a priori de un engaño típico a efectos del delito de estafa que no implique una puesta en escena. En este contexto, al engaño lo forjamos como aquel comportamiento - cualquiera- que genere un riesgo típicamente relevante, para cuya idoneidad objetiva bastaría con que conciba un riesgo típicamente relevante de producción de un acto de disposición por error que desemboque en un perjuicio patrimonial.

$8^{a}$. El error no debería incluirse en el engaño, ya que conllevaría el absurdo de desvalorar en el tipo el comportamiento sólo en función de la diligencia de la víctima, su credibilidad, o educación. Entonces, la idoneidad para generar el error determinaría, no la existencia del engaño, sino, en su caso, su relevancia jurídicopenal. En este sentido, lo importante no sería el engaño, ni tampoco el engaño "bastante", sino el "engaño bastante para producir error en otro". Así, a efectos de la tipicidad de la estafa, el engaño sería "toda aquella conducta tendente a generar error en otra persona, realizada con fines defraudatorios, e idónea para conseguirlo". 
REJ - Revista de Estudios de la Justicia - No 12 - Año 2010 
Balmaceda / Araya - Engaño en la estafa: ¿una puesta en escena?

\section{BIBLIOGRAFÍA***}

* Álvarez ÁlvarEZ, Gregorio: «Capítulo VI. De las defraudaciones», en Comentarios al Código penal, AAVV, Luis Arroyo Zapatero (et. al.) (dirs.) / Nieto Martín - Pérez Cepeda (coords.), Iustel, Madrid, 2007 (ÁLVAREZ ÁLVAREZ, 2007).

* ANTOLISEI, Francesco: Manuale di Diritto Penale, Parte speciale I, a cura di Luigi Conti, Multa Pavcis, Milano, 2002 (ANTOLISEI, 2002).

* ANTÓN ONECA, José: voz «Estafa», en NEJ, Calos-E. Mascareñas (dir.), Tomo IX, Editorial Francisco Seix, Barcelona, 1958 (ANTÓN ONECA, 1958).

* ARroyo De las Heras, Alfonso: Los delitos de estafa y falsedad documental, Bosch, Barcelona, 2005 (ARROYO DE LAS HERAS, 2005).

* ARZT, Gunther: «Viktimologie und Strafrecht», en Monatsschrift für Kriminologie und Strafrechtsreform, No 67, 1984 (ARZT, 1984).

* BACIGALUPO, Enrique: Estudios sobre la Parte especial del Derecho penal, Akal, Madrid, 1994 (BACIGALUPO, 1994).

* BACIGAlupO, Enrique: «art. 248», en Comentarios al Código penal, Tomo 3, AAVV, Cándido Conde-Pumpido Tourón (dir.) / Jacobo López Barja de Quiroga (coord.), Bosch, Barcelona, 2007 (BACIGALUPO, 2007).

* BACIGALUPO, Enrique: Falsedad documental, estafa y administración desleal, Marcial Pons, Madrid, 2007 (BACIGALUPO, 2007-b).

* BAJO FERNÁNDEZ, Miguel / PÉREZ MANZANO, Mercedes: «Cap. VII. Estafa», en Delitos patrimoniales y económicos, Miguel Bajo Fernández / Mercedes Pérez Manzano / Carlos Suárez González, Manual de Derecho penal, Parte especial, Editorial Centro de Estudios Ramón Areces, Madrid, 1993 (BAJO FERNÁNDEZ / PÉREZ MANZANO, 1993).

* BAjO FERNÁNDEZ, Miguel: «art. 248», en Comentarios al Código Penal, AAVV, Manuel Cobo del Rosal (dir.), Tomo VIII, Edersa, Madrid, 2004 (BAJO FERNÁNDEZ, 2004-b).

* Berdugo, Ignacio (et. al.): Curso de Derecho penal, Parte general, ediciones experiencia, Barcelona, 2004 (BERDUGO, 2004).

* Bullemore, Vivian / MACKInNON, John: Curso de Derecho penal, Tomo IV, Parte especial, LexisNexis, Santiago, 2007 (BULLEMORE / MACKINNON, 2007).

* BUStos RAmíreZ, Juan: Manual de Derecho penal, Parte especial, Ariel, Barcelona, 1991 (BUSTOS RAMÍREZ, 1991).

* CAlderón CEREZO, Ángel / CHOClán mONTAlVO, José Antonio: Manual de Derecho penal. Tomo II. Parte especial, Deusto, Madrid, 2005 (CALDERÓN / CHOCLÁN, 2005).

* CANCIO MELIÁ, Manuel: Conducta de la víctima e imputación objetiva en Derecho penal. Estudio sobre los ámbitos de responsabilidad de víctima y autor en actividades arriesgadas, Bosch, Barcelona, 2001 (CANCIO MELIÁ, 2001).

* CARrara, Francesco: Programa de Derecho criminal, Parte especial, Vol. VI (traducción de José J. Ortega Torres y Jorge Guerrero), Temis, Bogotá, 1987 (CARRARA, 1987).

* CODERCH, Pablo / SILVA SÁNCHEZ, Jesús-María: Simulación y deberes de veracidad, Civitas, Madrid, 1999 (CODERCH / SILVA SÁNCHEZ, 1999).

* CRAMER, Peter / PERRON, Walter: «[ 263», en Strafgesetəbuch Kommentar, AAVV, Adolf Schönke/Horst Schröder/Peter Cramer (eds.), C.H. Beck, München, 2006 (CRAMER / PERRON, 2006).

* Choclán montalvo, José Antonio: El delito de estafa, Bosch, Barcelona, 2000 (CHOCLÁN MONTALVO, 2000).

\footnotetext{
*** Al lado de cada obra, entre paréntesis, se presenta la forma como aparece citada en el texto.
} 
REJ - Revista de Estudios de la Justicia - No 12 - Año 2010

* EtCHeberry, Alfredo: Derecho penal, Parte especial, Tomo III, Editorial Jurídica de Chile, Santiago, 1998 (ETCHEBERRY, 1998).

* FANELLI, Andrea: La truffa, Giuffrè, Milano, 1998 (FANELLI, 1998).

* FIAndaCA, Giovanni / MUSCO, Enzo: Diritto penale, Parte speciale, Vol. II, Tomo II, I delitti contro il patrimonio, Zanichelli editore, Bologna, 2005 (FIANDACA / MUSCO, 2005).

* GARCÍA RIVAS, Nicolás: «Estructura jurisprudencial del delito de estafa», en Estafas y falsedades (Análisis jurisprudencial), AAVV, Javier Boix Reig (dir.), Iustel, Madrid, 2005 (GARCÍA RIVAS, 2005).

* GARRIDO IRACHETA, Maricarmen: Evolución y jurisprudencia del delito de estafa en Chile, Memoria de prueba, Universidad de Talca, 1999 (GARRIDO IRACHETA, 1999).

* Garrido monTt, Mario: Derecho penal, Parte especial. Tomo IV, Editorial Jurídica de Chile, Santiago, 2002 (GARRIDO MONTT, 2002).

* GÓMEZ BENÍTEZ, José Manuel: «Función y contenido del error en el tipo de estafa», en ADPCP, 1985 (GÓMEZ BENÍTEZ, 1985).

* GONZÁLEZ RUS, Juan José: Los intereses económicos de los consumidores, Instituto Nacional del Consumo, Madrid, 1986 (GONZÁLEZ RUS, 1986).

* GONZÁleZ RUS, Juan José: «Delitos contra el patrimonio y contra el orden socioeconómico (V). Las defraudaciones. La estafa», en Derecho penal español, Parte especial, AAVV, Manuel Cobo del Rosal (coord.), Dykinson, Madrid, 2005 (GONZÁLEZ RUS, 2005).

* Groizard gómez de la SERnA, Alejandro: El Código penal de 1870, Tomo ViI, Esteban-Hermanos-Impresores, Salamanca, 1897 (GROIZARD GÓMEZ DE LA SERNA, 1897).

* GUDÍN RODRÍGUEZ-MAGARIÑOZ, Faustino: «Absolución de un delito de estafa a una curandera que cobró por comprometerse a curar a un enfermo terminal de cáncer (Comentario a la STS de 2 de febrero de 2007)», en RLP, No 38, 2007 (GUDÍN RODRÍGUEZ-MAGARIÑOZ, 2007).

* GUTIÉRREZ FRANCÉS, M ${ }^{a}$ Luz: Fraude informático y estafa, Ministerio de Justicia, Madrid, 1991 (GUTIÉRREZ FRANCÉS, 1991).

* HeNTIG, Hans von: Estudios de psicología criminal, III, La estafa (traducción de José maría Rodríguez Devesa), Espasa-Calpe, Madrid, 1980 (HENTIG, 1980).

* HERNÁNDEZ BASUALTO, Héctor: «Aproximación a la problemática de la estafa», en Problemas actuales de Derecho penal, AAVV, Universidad Católica de Temuco, Temuco, 2003 (HERNÁNDEZ BASUALTO, 2003).

* KINDHÄUSER, Urs: «La estafa como autoría mediata tipificada» (traducción de Jorge Perdomo Torres), en su: Estudios de Derecho Patrimonial, Grijley, Lima, 2002 (KINDHÄUSER, 2002).

* LÓpez BARJA De QUiRoga, Jacobo [et. al.]: Manual de Derecho penal, Parte especial, II, Akal, Madrid, 1990 (LÓPEZ BARJA DE QUIROGA, 1990).

* LUCARELli, Umberto: La Truffa, Cedam, Padova, 2002 (LUCARELLI, 2002).

* Magaldi Paternostro, M. José: «Cap. VI. De las defraudaciones», en Comentarios al Código penal, Tomo I, AAVV, CÓRDOBA RODA, Juan / GARCÍA ARÁN, Mercedes (dirs.), Marcial Pons, Madrid, 2004 (MAGALDI PATERNOSTRO, 2004).

* MAgGini, Attilio: La Truffa, Cedam, Padova, 1988 (MAGGINI, 1988).

* Mantovani, Ferrando: Diritto Penale, Parte Speciale II, Cedam, Padova, 2002 (MANTOVANI, 2002).

* MARTÍNEZ ESCAMILLA, Margarita: La imputación objetiva del resultado, Edersa, Madrid, 1992 (MARTÍNEZ ESCAMILLA, 1992).

- MERA FIGUEROA, Jorge: Fraude civil y penal. El delito de entrega fraudulenta, LexisNexis, Santiago, 2001 (MERA FIGUEROA, 2001). 
Balmaceda / Araya - Engaño en la estafa: ¿una puesta en escena?

* MERA F., Jorge / CASTRO M., Álvaro: Jurisprudencia penal de la Corte Suprema, LexisNexis, Santiago, 2007 (MERA / CASTRO, 2007).

* MESTRE DELGADO, Esteban: «Tema 13. Delitos contra el patrimonio y el orden socioeconómico», en Derecho penal. Parte especial, AAVV, Carmen Lamarca Pérez (coord.), Colex, Madrid, 2005 (MESTRE DELGADO, 2005).

* MIR PUIG, Santiago: Derecho penal, Parte general, Reppertor, Barcelona, 2005 (MIR PUIG, 2005).

* MIR PUIG, Santiago: Estado, pena y delito, Montevideo - Buenos Aires, B de F, 2006 (MIR PUIG, 2006).

* MUÑOZ CONDE, Francisco: Derecho penal, Parte especial, Tirant lo Blanch, Valencia, 2007 (MUÑOZ CONDE, 2007).

* NAMER, Sabrina: Estafa e imputación objetiva, Ad-Hoc, Buenos Aires, 2002 (NAMER, 2002).

* PASTOR MUÑOZ, Nuria: «Consideraciones sobre la delimitación del engaño típico en el delito de estafa», en El Funcionalismo en Derecho penal. Libro Homenaje al Profesor Günther Jakobs. Tomo II, AAVV, Eduardo Montealegre Lynett (Coord.), Universidad Externado de Colombia, Bogotá, 2003 (PASTOR MUÑOZ, 2003).

* PASTOR MUÑOZ, Nuria: La determinación del engaño típico en el delito de estafa, Marcial Pons, Madrid, 2004 (PASTOR MUÑOZ, 2004).

* PASTOR MUÑOZ, Nuria: «Tema 11. Delitos contra el patrimonio (II)», en Lecciones de Derecho penal, Parte especial, AAVV, Jesús-María Silva Sánchez (dir.) / Ramón Ragués i Vallès (coord.), Atelier, Barcelona, 2006 (PASTOR MUÑOZ, 2006).

* PECORELlA, Claudia: «art. 640», en Codice Penale Commentato, a cura di Emilio Dolcini e Giorgio Marinucci, Ipsoa, Vicenza, 2006 (PECORELLA, 2006).

* PEDRAZZI, Cesare: Ingano ed errore nei delitti contro il patrimonio, Giuffrè, Milano, 1955 (PEDRAZZI, 1955).

* PÉREZ DEL VALLE, Carlos: «El engaño omisivo en la estafa», en Curso de Derecho penal económico, AAVV, Enrique Bacigalupo (dir.), Marcial Pons, Madrid, 2005 (PÉREZ DEL VALLE, 2005).

* PÉREZ MANZANO, Mercedes: «Acerca de la imputación objetiva de la estafa», en Hacia un Derecho penal económico europeo. Jornadas en honor al profesor Klaus Tiedemann, AAVV, BOE, Madrid, 1995 (PÉREZ MANZANO, 1995).

* PÉREZ manZANO, Mercedes: «Las defraudaciones (I). Las Estafas», en Compendio de Derecho penal. Parte especial, Vol. II, AAVV, Miguel Bajo Fernández (dir.), Editorial Centro de Estudios Ramón Areces, Madrid, 1998 (PÉREZ MANZANO, 1998).

* PIÑA ROCHEFORT, Ignacio: Fraude de seguros, Editorial Jurídica de Chile, Santiago, 2006 (PIÑA ROCHEFORT, 2006).

* POLITOFF, Sergio / MATUS, Jean Pierre / RAMÍREZ, Ma Cecilia: Lecciones de Derecho penal chileno, Parte especial, Editorial Jurídica de Chile, Santiago, 2005 (POLITOFF / MATUS / RAMÍREZ, 2005).

* Queralt jIMÉNEZ, Joan J.: Derecho penal español, Parte especial, Atelier, Barcelona, 2008 (QUERALT JIMÉNEZ, 2008).

* QUiNTANO RIPOLLÉS, Antonio: Tratado de la Parte especial del Derecho penal, II, Editorial Revista de Derecho Privado, Madrid, 1977 (QUINTANO RIPOLLÉS, 1977).

* QUiNTERO OLIVARES, Gonzalo: «Mitos y racionalidad en el delito de estafa (Apuntes sobre el significado práctico de la antijuridicidad)», en RDPP, N 3, 2000 (QUINTERO OLIVARES, 2000).

* Rebollo VARGaS, Rafael: «Engaño en el delito de estafa», en Diccionario de Derecho penal económico, AAVV, Javier Boix Reig (dir.) / Paz Lloira García (coord.), Iustel, Madrid, 2008 (REBOLLO VARGAS, 2008). 
REJ - Revista de Estudios de la Justicia - No 12 - Año 2010

* Rodríguez Devesa, José María / SERrano GÓMEZ, Alfonso: Derecho penal español, Parte especial, Dykinson, Madrid, 1995 (RODRÍGUEZ DEVESA / SERRANO GÓMEZ, 1995).

* ROMERO, Gladys: Delito de estafa, Hammurabi, Buenos Aires, 2007 (ROMERO, 2007).

* ROXIN, Claus: Derecho penal, Parte general. Tomo I. Fundamentos. La estructura de la teoría del delito (traducción de Diego-Manuel Luzón Peña, Miguel Díaz y García Conlledo, y de Javier de Vicente Remesal), Civitas, Madrid, 1997 (ROXIN, 1997).

* SILVA SILVA, Hernán: Las estafas, Santiago, Editorial Jurídica de Chile, 2005 (SILVA SILVA, 2005).

* SUÁreZ GONZÁLEZ, Carlos: «De las estafas», en Comentarios al Código penal, AAVV, Gonzalo Rodríguez Mourullo (dir.) / Agustín Jorge Barreiro (coord.), Civitas, Madrid, 1997 (SUÁREZ GONZÁLEZ, 1997).

* TIEDEMANN, Klaus: «S 263», en LK, Tomo VI, De Gruyter Recht, Berlin, 1999 (TIEDEMANN, 1999).

* TORÍO LÓPEZ, Ángel: «Acción y resultado en la estafa procesal», en Estudios penales. Libro Homenaje al Prof. J. Antón Oncea, AAVV, Ediciones Universidad de Salamanca, Salamanca, 1982 (TORÍO LÓPEZ, 1982).

* VALLE MUÑIZ, José Manuel: «Tipicidad y atipicidad de las conductas omisivas en el delito de estafa», en ADPCP, 1986 (VALLE MUÑIZ, 1986).

* VAlle MUÑIZ, José Manuel: El delito de estafa, Bosch, Barcelona, 1987 (VALLE MUÑIZ, 1987).

* VILA MAYO, Juan Emilio: «Consideraciones acerca del engaño en la estafa», en DLL, Vol. III, 1984 (VILA MAYO, 1984).

* VILA MAYO, Juan Emilio: «Ensayo sobre la estructura del delito de estafa», en RGD, enero-febrero, 1988 (VILA MAYO, 1988).

* VILA MAYO, Juan Emilio: «Consideraciones acerca del contrato criminalizado», en RGD, julio-agosto, 1991 (VILA MAYO, 1991).

* VIVES ANTÓN, Tomás Salvador / GONZÁLEZ CUSSAC, José Luis: «Sección 1 , De las estafas», en Comentarios al Código penal de 1995, Vol. II, AAVV, Tomás Salvador Vives Antón (coord.), Tirant lo Blanch, Valencia, 1996 (VIVES ANTÓN / GONZÁLEZ CUSSAC, 1996).

* VIVES ANTÓN, Tomás Salvador / GONZÁLEZ CUSSAC, José Luis: «Delitos contra el patrimonio y el orden socioeconómico (VII): Estafas», en Derecho penal, Parte especial, AAVV, Tomás Salvador Vives Antón (et. al.), Tirant lo Blanch, Valencia, 2004 (VIVES ANTÓN / GONZÁLEZ CUSSAC, 2004).

* YUBero CANEPA, Julio: El engaño en el delito de estafa, Editorial Jurídica Conosur, Santiago, 1993 (YUBERO, 1993).

* ZANNOTTI, Roberto: La Truffa, Giufrè, Milano, 1993 (ZANNOTTI, 1993).

\section{Jurisprudencia citada}

* Sentencia del Sexto Tribunal de Juicio Oral en lo Penal de Talca 23/04/2008

* Sentencia del Segundo Tribunal de Juicio Oral en lo Penal de Santiago 16/05/08

* Sentencia de la Corte de Apelaciones de Santiago 03/01/1986

* Sentencia de la Corte de Apelaciones de Santiago 12/07/2004

* Sentencia de la Corte de Apelaciones de Santiago 20/03/2007

* Sentencia de la Corte de Apelaciones de Santiago 30/03/2007

* Sentencia de la Corte de Apelaciones de Santiago 06/12/2007

* Sentencia de la Corte de Apelaciones de Santiago 31/01/2008

* Sentencia de la Corte de Apelaciones de Santiago 14/11/2008 
Balmaceda / Araya - Engaño en la estafa: ¿una puesta en escena?

* Sentencia de la Corte de Apelaciones de San Miguel 22/07/1986

* Sentencia de la Corte de Apelaciones de San Miguel 22/03/1990

* Sentencia de la Corte de Apelaciones de San Miguel 26/11/2007

* Sentencia de la Corte de Apelaciones de San Miguel 03/12/2007

- Sentencia de la Corte de Apelaciones de Valparaíso 08/04/2008

* Sentencia de la Corte de Apelaciones de Valparaíso 03/06/2008

* Sentencia de la Corte de Apelaciones de Concepción 25/01/2008

* Sentencia de la Corte de Apelaciones de Concepción 07/07/2008

* Sentencia de la Corte de Apelaciones de Temuco 30/06/2008

* Sentencia de la Corte de Apelaciones de Temuco 07/07/2008

* Sentencia de la Corte de Apelaciones de Talca 06/08/2007

* Sentencia de la Corte de Apelaciones de Valdivia 28/10/1986

* Sentencia de la Corte de Apelaciones de Punta Arenas 27/10/1989

* Sentencia de la Corte de Apelaciones de Punta Arenas 27/11/1989

* Sentencia de la Corte de Apelaciones de La Serena 17/12/2002

* Sentencia de la Corte de Apelaciones de Rancagua 01/08/2008

* Sentencia de la Corte de Apelaciones de Arica 23/07/2008

* Sentencia de la Corte de Apelaciones de Iquique 27/17/2007

* Sentencia de la Corte Suprema 21/03/1995

* Sentencia de la Corte Suprema 17/07/2001

* Sentencia de la Corte Suprema 05/06/2006

* Sentencia de la Corte Suprema 05/09/2006

* Sentencia de la Corte Suprema 26/03/2007

* Sentencia de la Corte Suprema 06/08/2007

* Sentencia de la Corte Suprema 21/11/2007

* Sentencia de la Corte Suprema 12/12/2007

* Sentencia de la Corte Suprema 17/06/2008

* Sentencia de la Corte Suprema 26/06/2008

* Sentencia del Tribunal Supremo español 13/05/1997

* Sentencia del Tribunal Supremo español 30/10/1997

* Sentencia del Tribunal Supremo español 7/11/1997

* Sentencia del Tribunal Supremo español 17/11/1997

* Sentencia del Tribunal Supremo español 4/02/1998

* Sentencia del Tribunal Supremo español 2/03/1998

* Sentencia del Tribunal Supremo español 5/05/1998

* Sentencia del Tribunal Supremo español 17/07/1998

* Sentencia del Tribunal Supremo español 20/07/1998

* Sentencia del Tribunal Supremo español 21/10/1998 
REJ - Revista de Estudios de la Justicia - No 12 - Año 2010

* Sentencia del Tribunal Supremo español 30/10/1997

* Sentencia del Tribunal Supremo español 7/11/1997

* Sentencia del Tribunal Supremo español 5/11/1998

* Sentencia del Tribunal Supremo español 27/01/1999

* Sentencia del Tribunal Supremo español 26/02/1999

* Sentencia del Tribunal Supremo español 28/01/1999

* Sentencia del Tribunal Supremo español 1/03/1999

* Sentencia del Tribunal Supremo español 24/03/1999

* Sentencia del Tribunal Supremo español 28/04/1999

* Sentencia del Tribunal Supremo español 4/05/1999

* Sentencia del Tribunal Supremo español 6/05/1999

* Sentencia del Tribunal Supremo español 9/06/1999

* Sentencia del Tribunal Supremo español 16/07/1999

* Sentencia del Tribunal Supremo español 1/12/1999

* Sentencia del Tribunal Supremo español 1/03/1999

* Sentencia del Tribunal Supremo español 1/03/2000

* Sentencia del Tribunal Supremo español 24/03/1999

* Sentencia del Tribunal Supremo español 6/03/2000

* Sentencia del Tribunal Supremo español 20/03/2000

* Sentencia del Tribunal Supremo español 28/03/2000

* Sentencia del Tribunal Supremo español 3/04/2000

* Sentencia del Tribunal Supremo español 18/01/2001

* Sentencia del Tribunal Supremo español 21/01/2002

* Sentencia del Tribunal Supremo español 29/01/2002

* Sentencia del Tribunal Supremo español 4/02/2002

* Sentencia del Tribunal Supremo español 8/04/2002

* Sentencia del Tribunal Supremo español 24/04/2002

* Sentencia del Tribunal Supremo español 6/05/2002

* Sentencia del Tribunal Supremo español 14/05/2002

* Sentencia del Tribunal Supremo español 27/05/2002

* Sentencia del Tribunal Supremo español 29/07/2002

* Sentencia del Tribunal Supremo español 24/09/2002

* Sentencia del Tribunal Supremo español 23/10/2002

* Sentencia del Tribunal Supremo español 28/11/2002

* Sentencia del Tribunal Supremo español 14/01/2003

* Sentencia del Tribunal Supremo español 12/03/2003

* Sentencia del Tribunal Supremo español 7/04/2003

* Sentencia del Tribunal Supremo español 8/04/2003

* Sentencia del Tribunal Supremo español 21/04/2003

* Sentencia del Tribunal Supremo español 5/05/2003

* Sentencia del Tribunal Supremo español 13/05/2003

* Sentencia del Tribunal Supremo español 22/05/2003

* Sentencia del Tribunal Supremo español 3/06/2003

* Sentencia del Tribunal Supremo español 9/06/2003

* Sentencia del Tribunal Supremo español 26/06/2003

* Sentencia del Tribunal Supremo español 27/06/2003

* Sentencia del Tribunal Supremo español 16/07/2003

* Sentencia del Tribunal Supremo español 24/07/2003

* Sentencia del Tribunal Supremo español 22/10/2003

* Sentencia del Tribunal Supremo español 27/11/2003

* Sentencia del Tribunal Supremo español 2/12/2003 
Balmaceda / Araya - Engaño en la estafa: ¿una puesta en escena?

* Sentencia del Tribunal Supremo español 5/12/2003

* Sentencia del Tribunal Supremo español 20/01/2004

* Sentencia del Tribunal Supremo español 28/01/2004

* Sentencia del Tribunal Supremo español 5/02/2004

* Sentencia del Tribunal Supremo español 12/02/2004

* Sentencia del Tribunal Supremo español 23/02/2004

* Sentencia del Tribunal Supremo español 1/03/2004

* Sentencia del Tribunal Supremo español 25/03/2004

* Sentencia del Tribunal Supremo español 2/04/2004

* Sentencia del Tribunal Supremo español 7/05/2004

* Sentencia del Tribunal Supremo español 17/05/2004

* Sentencia del Tribunal Supremo español 6/07/2004

* Sentencia del Tribunal Supremo español 22/09/2004

* Sentencia del Tribunal Supremo español 2/11/2004

* Sentencia del Tribunal Supremo español 5/11/2004

* Sentencia del Tribunal Supremo español 28/01/2005

* Sentencia del Tribunal Supremo español 15/02/2005

* Sentencia del Tribunal Supremo español 17/02/2005

* Sentencia del Tribunal Supremo español 23/03/2005

* Sentencia del Tribunal Supremo español 2/02/2007 